\title{
Presidential Address: Asset Price Dynamics with Slow-Moving Capital
}

\author{
DARRELL DUFFIE*
}

\begin{abstract}
I describe asset price dynamics caused by the slow movement of investment capital to trading opportunities. The pattern of price responses to supply or demand shocks typically involves a sharp reaction to the shock and a subsequent and more extended reversal. The amplitude of the immediate price impact and the pattern of the subsequent recovery can reflect institutional impediments to immediate trade, such as search costs for trading counterparties or time to raise capital by intermediaries. I discuss special impediments to capital formation during the recent financial crisis that caused asset price distortions, which subsided afterward. After presenting examples of price reactions to supply shocks in normal market settings, I offer a simple illustrative model of price dynamics associated with slow-moving capital due to the presence of inattentive investors.
\end{abstract}

I ADDRESS THE IMPLICATIONS for asset price dynamics of the apparent slow movement of investment capital to trading opportunities. The arrival of new capital to an investment opportunity can be delayed by fractions of a second in some markets, for example an electronic limit-order-book market for equities, or by months in other markets, such as that for catastrophe risk insurance. Accordingly, prices respond to supply or demand shocks with a sharp reaction because of the relatively small subset of capital (and thus risk-bearing capacity) that is immediately available to absorb a shock on short notice. Such a price impact is substantially reversed over time as additional capital becomes available. The amplitude of the immediate price impact and the pattern of the subsequent recovery can reflect many sorts of attention costs to trade as well as institutional impediments to capital movement, such as search costs for trading

*Darrell Duffie is at the Graduate School of Business, Stanford University. I am grateful to the American Finance Association for the opportunity to present this Presidential Address at the Annual Meeting of the American Finance Association in Atlanta in January, 2010. This written version of the address generally follows the lines of the original oral presentation, while adding details. I am pleased to acknowledge conversations or collaboration with Fernando Alvarez, Adam Ashcraft, David Bates, Stephen Buser, Lauren Cohen, Alex Edmans, Alessio Farhadi, Nicolae Gârleanu, Gaston Giroux, Jeremy Graveline, Denis Gromb, Christian Lundblad, Semyon Malamud, Gustavo Manso, Stefan Nagel, David Ng, Antti Petajisto, Lasse Pedersen, Adam Reed, Jay Ritter, Bruno Strulovici, Tong-Sheng Sun, Felipe Varas, Dimitri Vayanos, Pierre-Olivier Weill, and Hongjun Yan. I am especially grateful to Alex Edmans, Itay Goldstein, Jeremy Graveline, Wei Jiang, Jan Peter Kulak, Mark Mitchell, Yigal Newman, David Ng, Todd Pulvino, Michael Rierson, Eric Stafford, and Hongjun Yan for providing me with figures or data. I also benefited from expert research assistance by Felipe Varas, Kevin Wu, and Haoxiang Zhu. 


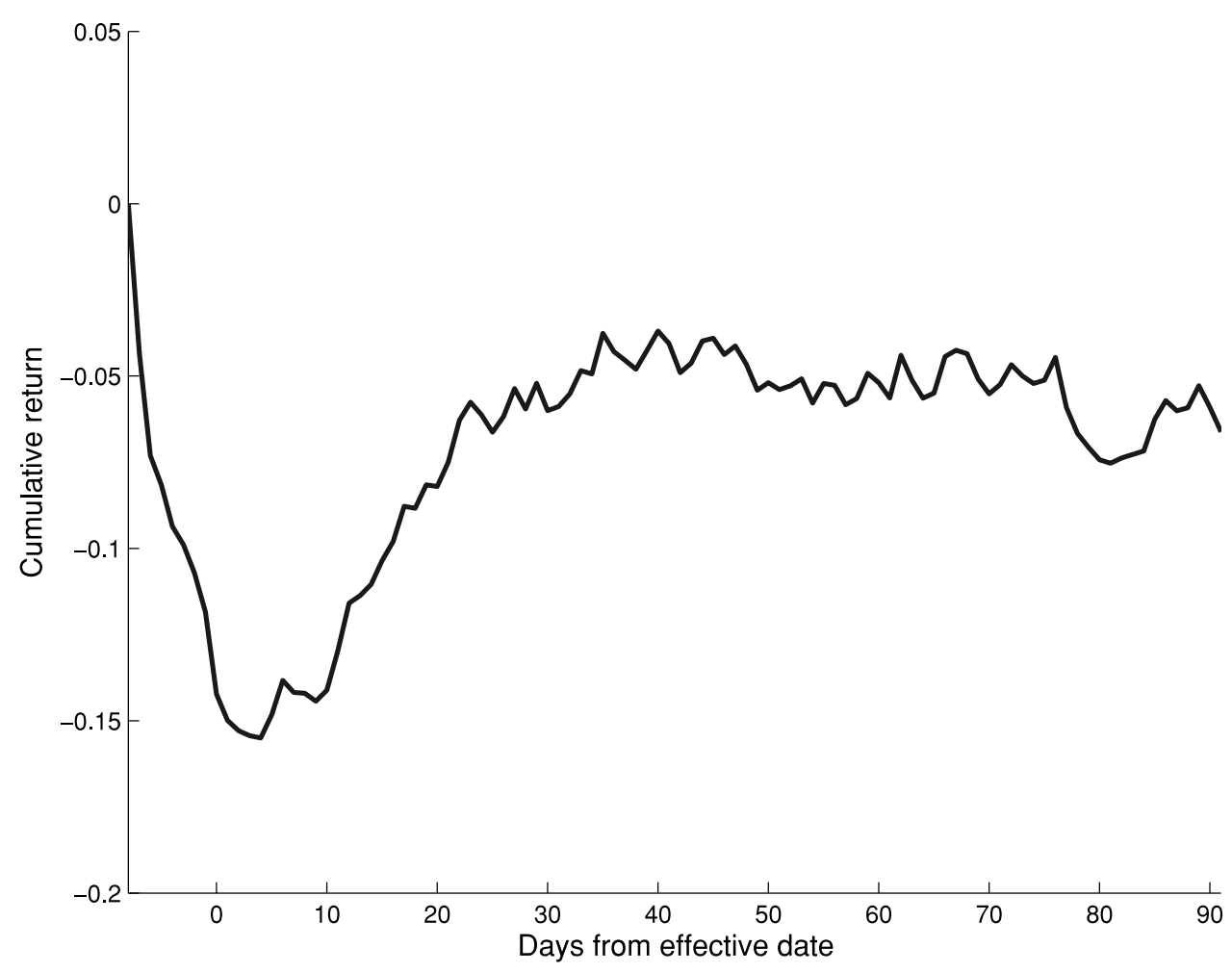

Figure 1. Average cumulative returns for deleted S\&P 500 stocks, 1990-2001. The average number of days between the announcement and effective deletion dates is 7.56. The passage of time from announcement to deletion for each equity is re-scaled to 8 days before averaging the cumulative returns during this period across the equities. The original data provided by Jeremy Graveline were augmented by Haoxiang Zhu.

counterparties or time to raise capital by intermediaries. I will discuss special impediments to capital formation during the financial crisis of 2007-2009 that caused unusual asset price distortions, which subsided as financial intermediaries regained capital. Motivated by various examples of price reactions to supply shocks in more normal market settings, Section V of this paper presents a simple illustrative model of price impacts and reversals caused by the presence of infrequently trading investors. Casual introspection and the empirical evidence reviewed in Section IV suggest that many investors make infrequent investment decisions. A simple explanation is that trading takes time away from valuable alternative activities.

\section{A. Motivating Example 1: Index Deletions}

As an initial motivating example, Figure 1 illustrates the average price impact of deletions of equities from the S\&P 500 stock index, and the associated average degree of price reversal. The underlying data, provided by Jeremy 
Graveline, cover the period from December 1990 to July 2002, and include 61 such deletions. The time from the announcement date to the effective date averaged about 7.5 days. As reported by Chen, Noronha, and Singhal (2004, p. 1910) for a similar data set, deleted stocks suffered a loss of approximately $8 \%$ on the announcement date and an additional loss of $6 \%$ between the announcement date and the effective deletion date. Quoting the authors, who cite several studies that further support this remarkable price impact and reversal, "The negative effect of deletions disappears completely 60 days after the effective date. The cumulative abnormal return from announcement to 60 days after the effective date is not significantly negative, and always economically small." Related studies of price impacts and recoveries associated with index recompositions, including both debt and equity indices, include those of Shleifer (1986), Harris and Gurel (1986), Madhavan (2001), Greenwood (2005a), Mitchell, Pulvino, and Stafford (2002), Wurgler and Zhuravskaya (2002), Kaul, Mehrotra, and Morck (2000), Coudert and Gex (2008), Chen et al. (2009), and Feldhütter (2009). Petajisto (2009) provides a model in which the pressure is borne by intermediaries, and applies his model to explain the empirical evidence on index deletions.

A substantial amount of investment is index based. Upon the decision by Standard and Poors to remove a particular equity from the S\&P 500, the index funds whose responsibility is to track this index have an extremely high incentive to sell the deleted equity on the effective date. ${ }^{1}$ From the degree of price impact reflected in Figure 1, it appears that a relatively limited set of investors were actively considering the purchase of these deleted equities near the effective date. They required substantial price concessions. It is likely that many of these investors planned to sell their positions over time to investors who, on the effective date, were not immediately available or aware of the opportunity to buy. Anticipation of the price at the effective date appears to have lead to a substantial reduction in price between the announcement and effective dates.

As years pass, more and more investors learn about trading opportunities presented by particular types of supply shocks such as index recompositions. Market architecture and asset-management practices are also adjusted over time and tend to reduce the related inefficiencies. The relative amount of capital available to absorb a particular type of supply shock therefore increases secularly, diminishing the price impacts and speeding up the price reversals. In this sense, capital mobility is a highly endogenous property of financial markets that presents special modeling challenges.

\section{B. Motivating Example 2: Price Impacts on Limit Order Books}

Even in markets that are extremely active, price dynamics reflect "slow capital" when viewed from a high-frequency perspective. Taking the case of an electronic limit-order-book market, the high speed with which many investors

\footnotetext{
${ }^{1}$ Blume and Edelen (2001) explain why it makes little sense, from a risk-return perspective, for an index fund to avoid selling the deleted shares on or near the effective date.
} 
are prepared to refresh their orders implies that price impacts caused by supply shocks may be largely reversed within a few seconds, if not much more quickly. For example, a relatively large order to sell at time $t$ is likely to receive immediate execution not only from the best available bid, (because the best bid is often for a smaller quantity than the sell order) but also from limit orders to buy at successively lower bid prices. The price impact is the drop from the last execution price $p(t-)$ before $t$ to the price $p(t)$ of the lowest limit order to buy that is hit by the sell order. (The impact could alternatively be measured from the bid-offer midpoint.) The immediate price impact $p(t)-p(t-)$ is thus increasing in the size of the sell order. Quickly, although not instantaneously, new bids arrive on the limit order book. Inference is drawn over the likelihood that the sell order was motivated by information about the future cash flows of the asset that may have been held privately by the seller as opposed to liquidation motives unrelated to private information. The first new bid to arrive after $t$ by an investor aware of the price impact would likely be placed at a price level $p(t+)$ that is above $p(t)$ but opportunistically low relative to expected future prices, in an attempt to exploit the likelihood that the investor is among the first to arrive after the price impact. To the extent that there is heterogeneity of order submission speed across liquidity-providing investors, those who place the first new bids to arrive are indeed aware of their likely opportunity to buy low from a new seller whose order may arrive soon afterward. Over time, the ability to achieve such a price concession deteriorates, as more and more investors have had the opportunity to assess the situation and place orders. The expected execution price path climbs over time as new investors arrive and also as inference about the likely motivation of the original sell order converges, absent other informational shocks. On average, the price is not expected to fully recover because some sell orders are based on new information. This brief description of one source of the dynamics of price impact and recovery is far from complete or rigorous, and is merely intended to give a sense of the interplay between the roles of inference, strategic liquidity provision, and delays in order placement. Biais, Hillion, and Spatt (1995) provide some empirical evidence. Relevant theories are provided by Goettler, Parlour, and Rajan (2005, 2008), Rosu (2009), and Biais and Weill (2009), who directly treat price impacts and reversals. In an idealized market with instant order placement, the associated price reactions and reversals are likely to be much smaller that those we observe in functioning electronic-communication-network markets.

\section{Motivating Example 3: Catastrophe Risk Premium Dynamics}

In some markets, extremely slow capital movement leads to price reversals that continue over many months. For example, Froot and O'Connell (1999), Zanjani (2002), and Born and Viscusi (2006) explain how premiums for catastrophe risk insurance typically increase dramatically when insurance and reinsurance firms suffer significant damage claims after natural disasters such as Hurricane Andrews in 1992. Premiums then drop toward "soft-market" levels over many months (absent other shocks to the capital of insurers) because the 
replacement of insurance capital is delayed by institutional barriers to capital raising, including the time spent searching for suitable new investors. Premiums swing up and down by as much as $50 \%$ over multi-year periods, according to Enz (2001). Institutional barriers to capital raising are considered in Section III. As explained by Enz (2001), catastrophe insurance premiums change significantly with shocks to the capital levels of insurers, whether they are caused by damage claims or by unexpected returns to the asset portfolios of insurers. From this fact, we know that the dynamics of insurance premiums after a major natural catastrophe are not caused mainly by inference concerning the arrival rate of future such events. We also know that most of the observed price impacts are not caused by inference about losses because major changes over time in insurance premiums following shocks to capital levels are highly correlated across all major lines of property insurance covered by the same pools of capital covering catastrophe risk. ${ }^{2}$ (These other lines cover, for example, aviation, marine, motor, and proportional property.) The link tying premium dynamics across the various lines of insurance is the level of capital commonly available to bear losses. Froot and O'Connell (1999) emphasize the slow speed of capital replacement as the major cause of slow premium adjustments.

I organize the remainder of this article as follows. Section II reviews the implications for asset price dynamics of trading delays caused by search frictions in over-the-counter (OTC) markets. Securities lending is emphasized as a motivating case. Section III considers limits on the ability of market intermediaries to quickly move investors' capital from one trading opportunity to another. Here, I emphasize search frictions as well as the ability of an intermediary to absorb supply shocks when its risk-bearing capital is limited. Barriers to capital raising by intermediaries themselves, especially during the financial crisis of 2007-2009, receive special attention.

Section IV turns away from institutional frictions to consider instead delays caused by the limited attention that investors allocate to their trading decisions. Section V offers a simple illustrative general equilibrium model of price dynamics caused by supply shocks in the presence of investors that trade infrequently. This section includes a discussion of the implications of three types of supply shocks: (1) observable shocks that take the market by surprise, (2) observable shocks, such as bond and equity issuances, that are anticipated, and finally (3) supply shocks whose magnitudes are imperfectly observed. Section VI concludes with a summary of the perspective offered by this paper.

\section{Traded Delayed by Search}

In OTC markets such as those for many types of bonds, derivatives, and securities lending, trade can be delayed by market opaqueness. Investors search for appropriate counterparties. Search times can be extended by "shopping around" when there is significant uncertainty regarding the potential terms of trade available from alternative counterparties. Larger price concessions

\footnotetext{
${ }^{2}$ See, for example, Enz (2001), page 5, Figure 1.
} 
are given by those who have limited opportunities to trade with counterparties. Theoretical approaches are offered by Wolinsky (1990), Duffie, Manso, and Malamud (2010), and Zhu (2010). Empirical evidence of opaqueness, reflected in the degree of heterogeneity across investors of execution prices, is given in various settings by Ashcraft and Duffie (2007), Goldstein, Hotchkiss, and Sirri (2007), Green, Hollifield, and Schürhoff (2007a,b), and Green, Li, and Schürhoff (2008).

In financial markets in which trade is delayed by search, supply shocks cause price impacts and reversals. For example, delayed access to shares in the equity lending market are shown by Blocher, Reed, and Van Wesep (2010) to lead to price elevations of around $1 \%$ around dividend dates, which subsequently decay. It takes time to locate suitable lenders of securities, which conveys bargaining power to lenders of shares that are in high demand by borrowers. Lending fees are sometimes large, as documented by D'Avolio (2002) and Geczy, Musto, and Reed (2002). A like effect causes the prices of U.S. Treasuries to be temporarily elevated while they are on "special" in repo markets, as explained by Duffie (1996). ${ }^{3}$ In this setting, the asset price reflects both the dividend stream of the underlying security as well as the potential opportunity to lend the security in return for borrowing fees. All owners receive the dividends, but only those owners who are matched to securities borrowers obtain the additional lending fees, as emphasized by Banerjee and Graveline (2010). Duffie, Gârleanu, and Pedersen (2002) provide an accompanying theory of price determination. Over time, as the assets on loan are sold and successively relent and sold, the demands of securities borrowers are gradually met and the present value of rents to lenders declines, absent additional shocks to supply or demand. Without search delays, the demands of borrowers for shares would be met by the immediate recirculation of securities through the OTC market; there would be no rents to securities lenders.

Duffie, Gârleanu, and Pedersen (2007) provide a model for OTC-market price impacts and reversals caused by shocks to the preferences of investors. If the original natural owners of the asset suffer a shock that causes them to be natural sellers of the asset, the price immediately drops and recovers over time as new natural owners of the asset are found and are sold the asset. As illustrated in Figure 2, the size of the immediate price reaction and the halflife of its reversal are decreasing in the mean rate at which investors locate suitable counterparties.

In practice, search delays may be small but can be effectively augmented by other institutional impediments to immediate trade, such as time to negotiate, time to prepare and authorize bilateral contracts, time for delegated asset managers to consult or re-contract with clients, and so on. In the case of catastrophe insurance, discussed in Section I, for example, setting up and capitalizing appropriately licensed insurance entities could involve substantial delays. In the next section, I discuss impediments to recapitalizing existing insurers.

\footnotetext{
${ }^{3}$ For more evidence, see Banerjee and Graveline (2010).
} 

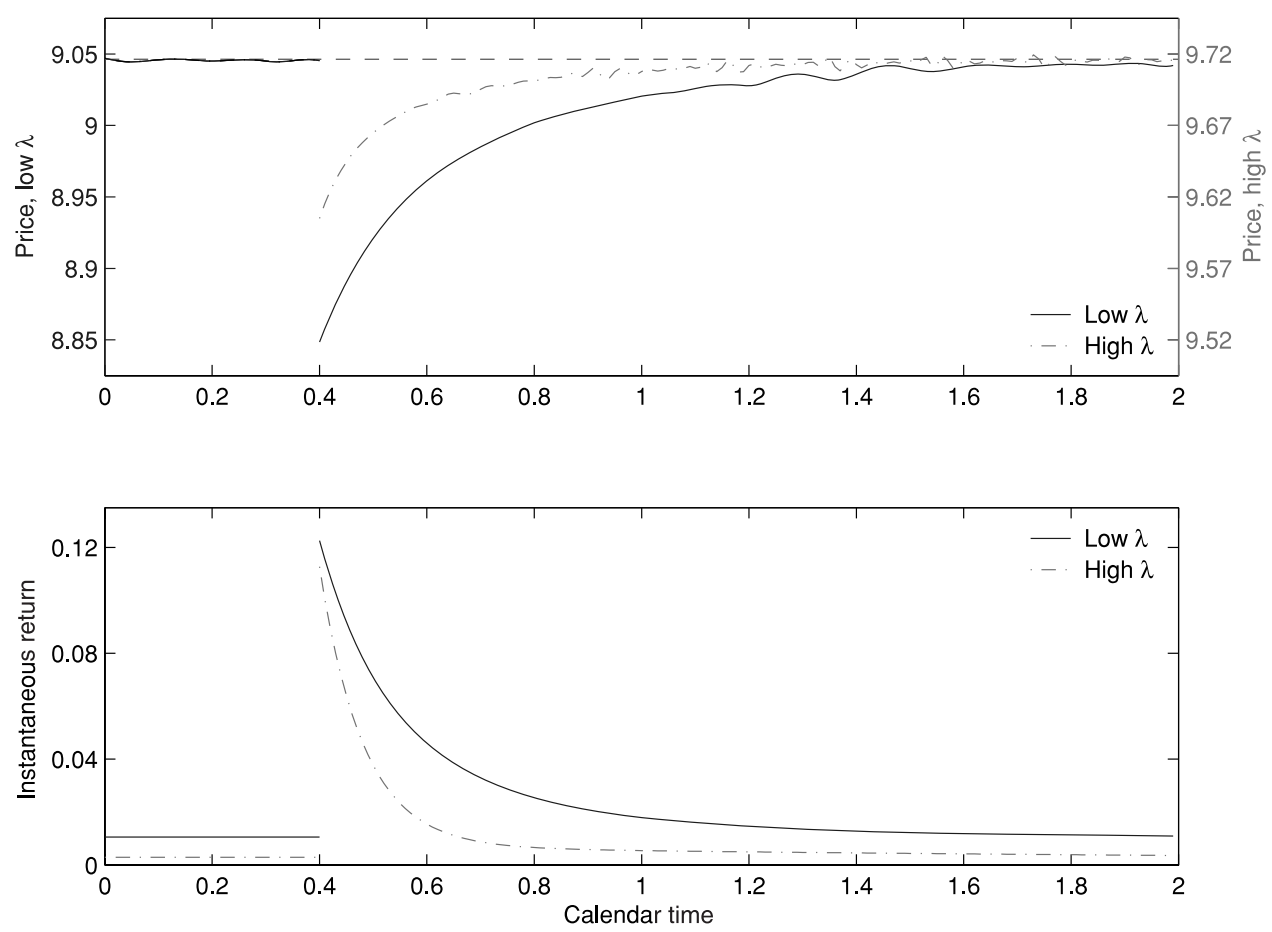

Figure 2. Price reaction to investor preference shocks in an idealized OTC market, with various alternatives for the mean rate $\lambda$ at which counterparties are located. Source and model details: Duffie, Gârleanu, and Pedersen (2007).

\section{Limits on Capital Market Intermediation}

A significant amount of investment is intermediated, for example, by brokers, dealers, specialists, general partners of private investment funds, and asset managers. Intermediaries may take time to move investors' capital from one investment opportunity to another. They may also themselves bear risk in order to act as intermediaries, as emphasized by Grossman and Miller (1988). As a result, when there are surges in demand or supply, new arrivals of information about future asset cash flows, or shocks to the capital of intermediaries, initial price adjustments may be larger than they would be in a market with perfect intermediation, and at least partial reversals of these price adjustments will occur over time as the process of intermediation continues to "digest" the initial shocks.

A wealth of empirical evidence of price surges and return reversals caused by specialist inventory imbalances has been provided by Andrade, Chang, and Seasholes (2005), Hendershott and Seasholes (2007), and Hendershott and Menkveld (2009). This is consistent with the theory of Grossman and Miller (1988). Dealers and specialists offer immediacy to buyers and sellers whose orders arrive asynchronously. Intermediaries profit by absorbing order 

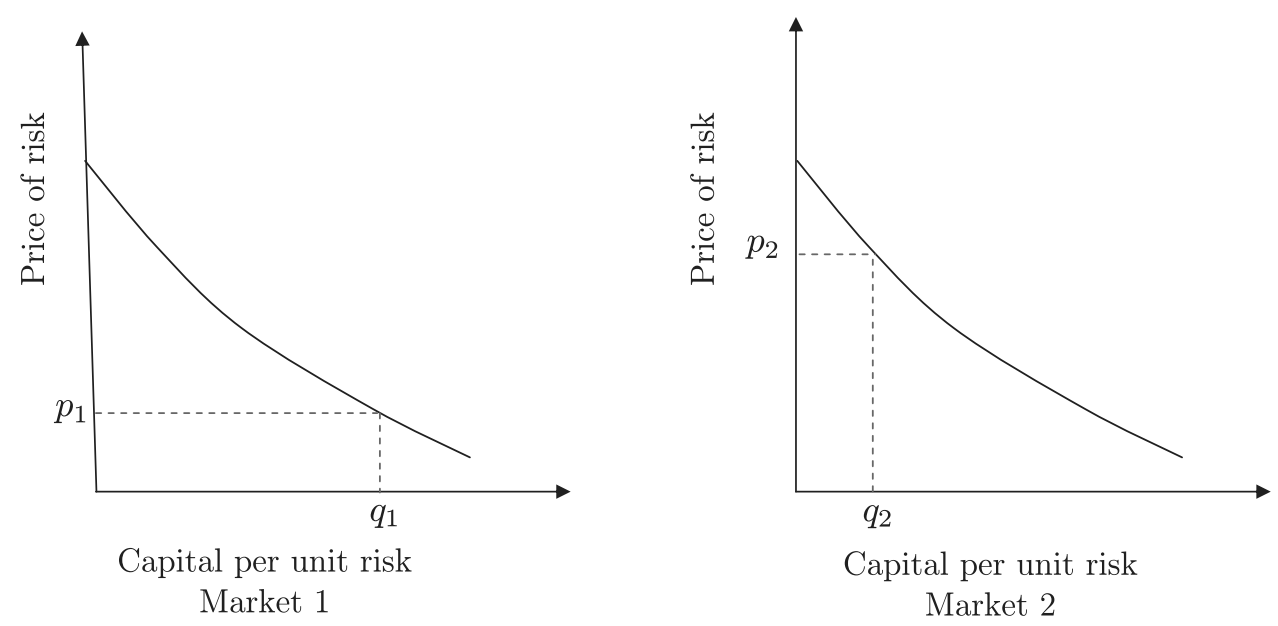

Figure 3. Capital migrates over time from a market with a low risk premium and excess capital to a market with a high risk premium.

imbalances until they can be reduced. Nagel (2009), Lou (2009), and Rinne and Suominen (2010) offer additional evidence on return reversals due to price pressure, as suggested in the theory of Weill (2007).

Gromb and Vayanos (2002), He and Krishnamurthy (2009), Gromb and Vayanos (2010), Lagos, Rocheteau, and Weill (2009), Rinne and Suominen (2009), Brunnermeier and Pedersen (2009), and Duffie and Strulovici (2009) provide various dynamic asset pricing theories based on intermediated movement of capital to trading opportunities, in which the limited capacity of intermediaries leads to distortions in risk premia, relative to neoclassical asset pricing models. Illustrating some of this literature, Figure 3 suggests the movement of capital from an "over-capitalized investment" to an investment opportunity that is "under-capitalized." Intermediaries have a greater incentive to move the capital of investors when the difference in the risk premia across markets is larger. This leads to mean reversion in risk premia.

If the balance-sheet capacity of dealers is depleted, their ability to intermediate markets is reduced. They become less able or predisposed to absorb supply and demand shocks, and to hold buffer inventories of assets. When this happens, one expects the market value of risky assets to decline commensurately. For example, Meli (2004) found evidence that changes in dealer capital are strongly related to changes in swap spreads (the difference between swap rates and treasury rates). Etula (2009) describes how variation over time in broker-dealer assets is significantly correlated with crude oil returns. Further evidence on the relationship between dealer risk-bearing capacity and distortions in risk premia is provided by Adrian, Etula, and Shin (2009) and Adrian, Moench, and Shin (2010). In related work, Mitchell, Pedersen, and Pulvino (2007) provide a range of distortions in the prices of certain assets that have appeared when arbitrageurs that specialized in these assets suffered 


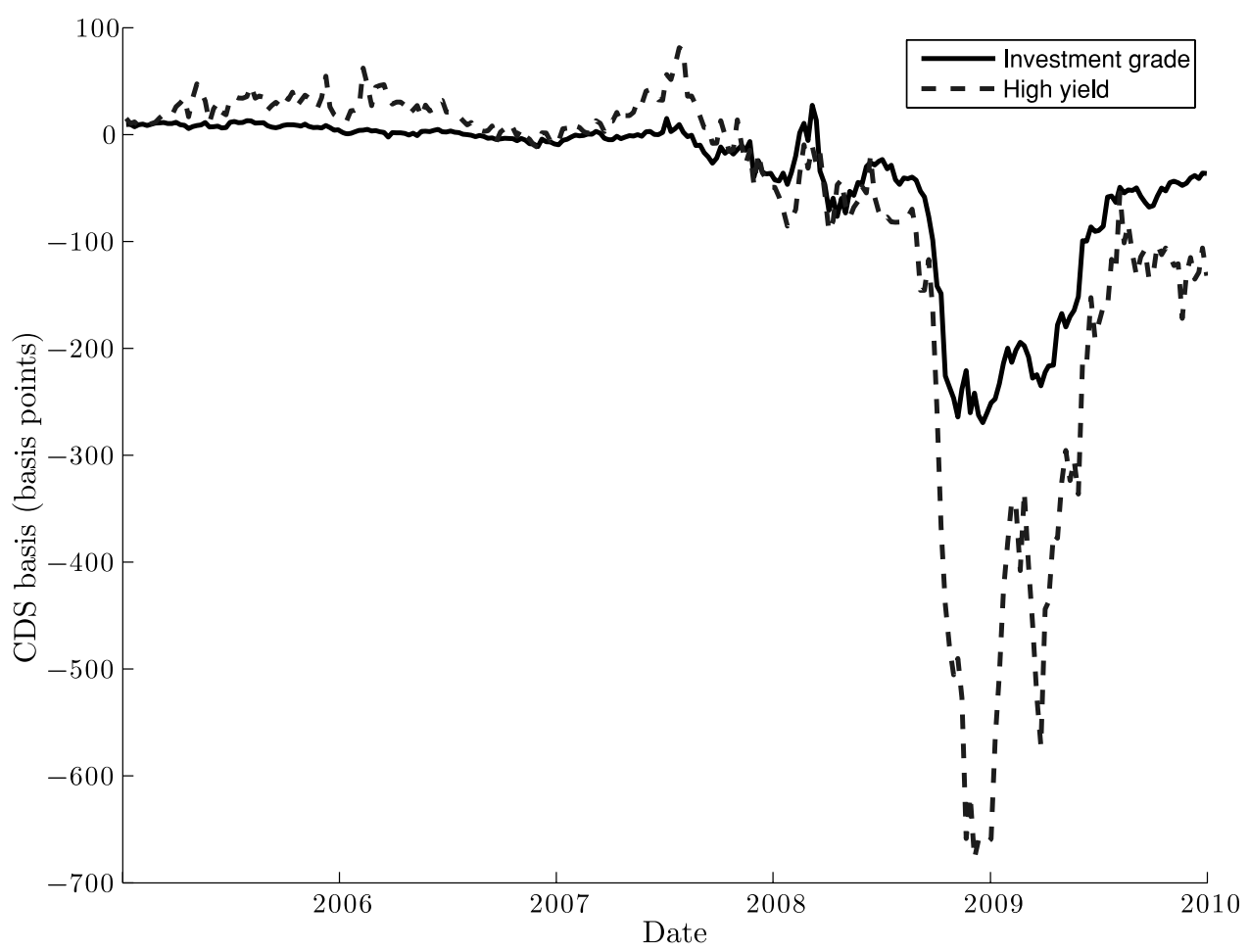

Figure 4. The corporate-bond CDS basis, the difference between the CDS rate and the associated par bond yield spread, is theoretically near zero in frictionless markets. As shown, the average CDS basis across portfolios of U.S. investment-grade bonds and high-yield bonds widened dramatically during the financial crisis and then narrowed as the crisis subsided. The underlying data, kindly provided to the author by Mark Mitchell and Todd Pulvino, cover an average of 484 investment-grades issuers per week and 208 high-yield issuers per week. For additional details, see Mitchell and Pulvino (2010).

significant losses in capital. Malliaris and Yan (2010) propose the reputation concerns of fund managers as a potential contributor to slow-moving capital in similar settings.

\section{A. Financial-Crisis Distortions in the Credit Default Swap Basis}

During the financial crisis of 2007-2009, the depletion of dealer capital was so severe that, among other effects, large distortions in arbitrage-based pricing relationships appeared.

For example, data from Mitchell and Pulvino (2009) displayed in Figure 4 illustrate a dramatic violation during the financial crisis of an "arbitrage" relationship between bond yield spreads and credit-default swap (CDS) rates. A credit default swap is a derivative security. The CDS rate is the annual premium, as a fraction of the principal value of a specified debt instrument, 
paid for coverage of default losses (principal value less default recovery value), should the named debt instrument default before the maturity of the CDS. In an arbitrage-free frictionless market, ${ }^{4}$ the CDS rate is, within a small tolerance for technical contract differences, equal to the yield spread on a par bond of the maturity of the CDS of the same issuer, that is, the bond yield less the associated risk-free yield. The difference between the CDS rate and the bond spread is known as the "basis." If, for example, the basis for a particular corporate bond becomes negative, as illustrated in Figure 4, one could short a risk-free bond, invest the proceeds in the corporate bond, and buy default protection on the corporate bond with a credit default swap. Putting aside some technical issues and ignoring counterparty risk, the net income of this strategy per year, at no net initial investment, is the principal debt position multiplied by the absolute magnitude of the basis. If the basis becomes negative, the opposite trade is likewise highly profitable, although holding a short position in corporate bonds is somewhat cumbersome and can involve extra costs or risks. Institutional details can cause the basis to diverge somewhat from zero. For example, if the CDS counterparty is risky, the basis can become somewhat negative.

The extremely negative CDS basis "violation" illustrated in Figure 4, across broad portfolios of investment-grade bonds and high-yield bonds, respectively, is far too large to be realistically explained by CDS counterparty risk or by other minor technical details. As suggested by Mitchell and Pulvino (2009), the most plausible explanation is a shortage of capital held during the financial crisis by the major dealer banks. Exploiting the CDS basis "arbitrage" calls for a substantial amount of balance-sheet capacity at dealer banks, both to make markets in the underlying bond (which calls for finding or holding the underlying bonds) and to handle two CDS counterparty positions, one with the arbitrageur and one with a counterparty taking the opposite position. Exacerbating the capital shortage of dealers, the amount of capital necessary to hold corporate bonds increased because of an increase in the "haircut" applied to finance corporate bonds in the repo markets, as explained by Mitchell and Pulvino (2009). As large dealers regained some balance-sheet capacity with improvements in market conditions and with some capital raising, the CDS basis went back toward normal, as illustrated.

The major dealer banks seemed generally slow to raise new capital in response to the profit opportunities represented by the CDS basis distortion illustrated in Figure 4, among other unusual price distortions that appeared during the financial crisis of 2007-2009. Perhaps these banks were so undercapitalized that the debt-overhang effect explained by Myers (1984) dominated these opportunities. That is, a significant share of each dollar of equity raised by dealers would merely have improved the position of unsecured creditors, and represented a loss to existing shareholders. In any case, the extreme CDS basis shown in Figure 4 was not substantially reduced until the dealers were effectively forced to recapitalize by governments. In the United States, for instance, all major dealer banks were forced to accept capital injections from

\footnotetext{
${ }^{4}$ See Duffie (1999).
} 
the Troubled Asset Relief Program and some were subsequently required to raise additional capital in response to the Supervisory Capital Assessment Program. ${ }^{5}$ In light of these forced re-capitalizations, the timing of the reversal shown in Figure 4 is unlikely to reflect natural market forces.

\section{Investment Inattention}

A neoclassical model of dynamic asset pricing posits that all investors are focused at all times on adjusting their consumption levels and asset portfolios so as to equate marginal utilities of consumption to marginal indirect utilities of wealth invested in each of the assets. In reality, most investors are likely to be focusing on other tasks much of the time. It would be sub-optimal to continually focus one's attention on trading decisions. At any point in time, asset prices are likely to reflect the marginal trade-offs of a relatively thin subset of investors.

As an anecdotal illustration, on February 19, 2010, Patterson and Martin (2010) reported that "investors took time out from trading to watch [Tiger] Woods apologize for his marital infidelity and 'repeated irresponsible behavior.' New York Stock Exchange volume fell to about 1 million shares, the lowest level of the day at the time, in the minute Woods began a televised speech from Ponte Vedra Beach, Florida, headquarters of the U.S. PGA Tour. Trading shot to about 6 million when the speech ended, the highest for any period except just after exchanges opened, data compiled by Bloomberg show. Trading on all U.S. bourses declined during the press conference, falling to 456 million shares from an average of 576.8 million during the five previous 15-minute segments, Bloomberg data show."

A growing body of research considers the implications of attention costs for investment behavior. For example, Duffie and Sun (1990) propose a model in which each investment decision determines not only consumption levels and asset positions, but also sets an optimal "time out" during which the investor will focus attention on other activities, without making the effort to consider investment and consumption opportunities. In this model, a stock of risk-free liquid assets is set aside for consumption purchases during this period of inattention to investment. ${ }^{6}$ By setting up in this manner a transactions demand for cash, optimal investment inattention plays a natural role in monetary theory, as considered, for example, by Alvarez, Lippi, and Paciello (2010) and Alvarez, Guiso, and Lippi (2010).

A significant body of empirical evidence suggests that investors adjust their portfolios remarkably infrequently. For example, Ameriks and Zeldes (2004) report that over a 10 -year period, $44 \%$ of investors in their sample made no changes to their portfolio allocations, and that an additional $17 \%$ of these

\footnotetext{
${ }^{5}$ See Board of Governors of the Federal Reserve System (2009).

${ }^{6}$ Under strong parametric assumptions, including decision costs that are proportional to total wealth, the time between trades is deterministic in the steady state. Among other extensions to this model, Abel, Eberly, and Panageas (2009) generalize to allow for any initial level of liquid assets, in which case the time between trades is dependent on cash levels, eventually converging to the steady state delay.
} 
investors made a single re-allocation during this period. Mitchell et al. (2006) find that, of 1.2 million U.S. employees covered by over 1,500 401(k) investment plans, approximately $80 \%$ initiated no trades over a 2 -year period, while an additional $10 \%$ made only a single trade. ${ }^{7}$

Delays in processing information for purposes of investment decisions are also in evidence from "price momentum" following fundamental news, as documented empirically by Chan (2003), Engelberg, Reed, and Ringgenberg (2010), Dellavigna and Pollet (2009), and Cohen and Lou (2010), among others.

The implications of optimal investment inattention for asset price dynamics are distinct from those associated with classical transactions costs for adjustments to individual positions. Suppose, for example, that the transactions cost for each asset traded is some strictly increasing function of the traded amount, but that investors are constantly pursuing any utility-increasing trade with complete attention, as would a neoclassical investor of the type modeled by Constantinides (1986) and Davis and Norman (1990). At the time of a supply or demand shock, the entire population of investors would stand ready to absorb the quantity of the asset supplied or demanded, with an excess price concession relative to a neoclassical model that is bounded by marginal trading costs. After the associated price shock, price reversals would not be required to clear the market.

Here, I am most interested in the implications of investor inattention for asset price dynamics. If only a small subset of investors are making investment decisions at each point in time, markets are effectively thinner in the short run. Price impacts are therefore likely to be larger. This would show up empirically in higher short-run return volatility and in negatively correlated asset returns. By calibrating an equilibrium model of inattentive investors, Lynch (1996) is able to reconcile the low volatility of aggregate consumption and the low empirical correlation of market returns with aggregate consumption changes. Similarly, Caballero (1995), Gabaix and Laibson (2001), and Chien, Cole, and Lustig (2010) analyze the equilibrium implications of intermittent investor attention for the moments and cross moments of aggregate consumption and market returns.

\section{An Illustrative Model of Price Dynamics with Inattentiveness}

Rather than focusing on the implications of investor inattention for the moments of aggregate consumption and market returns, I offer a simple illustrative model of the implications for price impacts and reversals associated with supply shocks. My objective is a conceptual framework for the dynamics of

\footnotetext{
${ }^{7}$ For further evidence on the slowness of individual portfolio adjustments, see Lusardi (1999, 2003), Brunnermeier and Nagel (2008), and Bilias, Georgarakos, and Haliassos (2009). In order to motivate the live audience of this Presidential Address, I asked for a show of hands by those who had adjusted their financial portfolios in the preceding 2 weeks. Of several hundred financial economists present (presumably many of whom are sophisticated investors), a mere three or four individuals raised their hands.
} 
asset prices in settings in which only a subset of investors are actively investing at any point in time, given the costs of maintaining perfect attentiveness to trading opportunities. The key implication is that supply or demand shocks must be absorbed on short notice by a limited set of investors. The risk aversion or limited capital of the currently available investors leads them to require a price concession to absorb the supply or demand shock. They plan to "lay off" the associated risk over time as other investors become available. As a result, the initial price impact is followed by a gradual price reversal. I also examine the case of an anticipated supply shock. In this case, investors demand increasingly large price concessions in advance of a large scheduled increase in supply or demand.

To this end, I extend the standard dynamic general equilibrium model of Stapleton and Subrahmanyam (1978), based on Gaussian asset cash flows and additive-exponential utility (constant absolute risk aversion), by allowing an infinite time horizon and by presuming that a subset of agents make investment decisions infrequently.

Taking the simplifying approach of Lynch (1996), Gabaix and Laibson (2001), Bacchetta and van Wincoop (2010), and Chien et al. (2010), I suppose that some set of investors fix their periods of inattention, rather than solving for endogenous periods of inattention. These authors used simulation or approximation methods to solve their models. By taking a sufficiently simple case, I obtain an exact and analytically tractable solution of the equilibrium. In a model with i.i.d. asset price increments, Reis (2006) solves explicitly for the constant optimal period of inattentiveness of an investor. Endogenous inattention is difficult to solve here (at least for me) because of the nonstationarity associated with price impacts and reversals.

I suppose that some fraction $q$ of investors are "inattentive" for $k$ periods after each trade. The remaining fraction $1-q$ trade in every period. One may think of the frequently trading investors as those with a relatively low cost of attention to investment decision making. For example, the frequent investors could be viewed as professional intermediaries, as in the three-period model of Grossman and Miller (1988). The trading activities of the inattentive investors are evenly distributed across time, so that in any one period, a fraction $1 / k$ of them trade. Thus, the model of market participation has two parameters, $q$ and $k$.

The current exogenous supply $Z_{t}$ and dividend $X_{t}$ of the risky asset are assumed to form a jointly Gaussian and autoregressive process $\Phi_{t}=\left(Z_{t}, X_{t}\right)^{\top}$. That is,

$$
\Phi_{t+1}=\Lambda \Phi_{t}+\Sigma^{1 / 2} \epsilon_{t+1}
$$

where $\Lambda$ and $\Sigma$ are $2 \times 2$ matrices, with $\Sigma$ positive semi-definite and symmetric. (It is enough for the linear form of equilibrium analyzed here that $Z_{t}$ and $X_{t}$ are linear with respect to some vector autoregressive Gaussian process, as allowed for generality in the appendix.) 
There is also a risk-free asset with a constant per-period gross return of $r>1$ (an interest rate of $r-1$ ). As usual within this general setting, the riskfree return $r$ is not determinate in general equilibrium; we take it as given. I suppose for simplicity that inattentive investors have arranged for risky-asset dividends to be re-invested at the risk-free rate until their next investment decisions, so that the net proceeds at the next investment time $t+k$ associated with the purchase of one unit of the risky asset at time $t$ is

$$
R_{t+k}=S_{t+k}+\sum_{i=1}^{k} r^{k-i} X_{t+i},
$$

where $S_{t}$ is the price of the risky asset at time $t$.

Equilibrium is characterized by optimal investment decisions by each agent, and by the market-clearing condition that the sum of the aggregate current demand $D_{t}$ of inattentive investors and the aggregate demand $K_{t}$ of frequent investors is equal to the total available supply. That is,

$$
D_{t}+K_{t}=Z_{t}-D_{t-1}-D_{t-2}-\cdots-D_{t-k+1},
$$

noting that the positions taken by infrequent investors over the previous $k-1$ periods are not currently available to the market.

Investors live for a finite number of time periods and then consume their wealth, being replaced by arriving investors of the same type. The total lifetimes of the frequent and infrequent investors do not play a role in price behavior in any stationary equilibrium (because of the properties of exponential utility), except for the question of whether an equilibrium exists. Here, for simplicity, I merely assume and characterize a stationary equilibrium.

Letting $H_{t}=\left(D_{t-1}, D_{t-2}, \ldots, D_{t-k+1}\right)$ denote the vector of quantities held off the market by infrequent investors, we anticipate that an equilibrium stationary autoregressive Gauss-Markov state vector is given by $Y_{t}=\left(\Phi_{t}^{\top}, H_{t}\right)^{\top}$. Following a typical line of analysis in similar settings, I anticipate a stationary equilibrium price of the risky asset of the form $S_{t}=c \cdot Y_{t}$, for some $(k+1)$ dimensional coefficient vector $c$.

If this were so, the frequent investor demand would be of the form $K_{t}=$ $b(c) \cdot Y_{t}$ and the inattentive-investor demand would be of the form $D_{t}=a(c) \cdot Y_{t}$, for some coefficient vectors $a(c)$ and $b(c)$, respectively. Although these demand coefficient vectors depend implicitly on the risk-aversion coefficients of the agents and on the various exogenous parameters determining the distribution of the process $\Phi_{t}=\left(X_{t}, Z_{t}\right)$, the notation shows for simplicity only their dependence on the endogenous price-coefficient vector $c$.

The dynamics of the state vector $Y_{t}$ are now completely specified as an autoregressive time-homogeneous Gaussian process by noting that

$$
\begin{gathered}
H_{t+1,1}=D_{t}=a(c) \cdot Y_{t} \\
H_{t+1, i}=H_{t, i-1}, \quad i>1 .
\end{gathered}
$$


The dynamics for $Y$ can thus be expressed in the form

$$
Y_{t+1}=A(c) Y_{t}+B \epsilon_{t+1},
$$

where the matrices $A(c)$ and $B$ are fully determined by (1)-(3). Details are given in the appendix.

It follows that

$$
E\left(Y_{t+k} \mid Y_{t}\right)=A(c)^{k} Y_{t}
$$

The conditional expected change of the risky asset price from time $t$ to time $t+k$ is therefore $c^{\top}\left(A(c)^{k}-I\right) Y(t)$, where $I$ denotes the identity matrix. The variance of the change in asset price is $c^{\top} V_{t}\left(Y_{t+k}\right) c$, where $V_{t}(\cdot)$ denotes conditional variance given $Y_{t}$. Likewise, the conditional mean $\mu_{t, t+k}(c)$ and the conditional variance $\sigma_{t, t+k}^{2}(c)$ of the per-unit risky asset payoff $R_{t+k}$ of a time- $t$ inattentive investor can be calculated explicitly. These calculations are provided in the appendix. Crucially for our purposes, $\mu_{t, t+k}(c)$ is linear in $Y_{t}$ and $\sigma_{t, t+k}(c)$ is deterministic.

I let $\theta$ denote the harmonic mean ${ }^{8}$ of the absolute risk-aversion coefficients of the inattentive investors. If all such investors have the same risk-aversion coefficient, then $\theta$ is their risk aversion. Because the conditional variance is deterministic and the conditional mean $\mu_{t, t+k}(c)$ is linear with respect to $Y_{t}$, it follows that the total inattentive-investor demand

$$
D_{t}=\frac{q}{k} \frac{\mu_{t, t+k}(c)}{\theta \sigma_{t, t+k}^{2}(c)} \equiv a(c) \cdot Y_{t}
$$

is indeed linear in $Y_{t}$ as conjectured (assuming equilibrium).

Likewise, letting $\phi$ be the harmonic mean of the risk-aversion coefficients of the frequent investors, the demand of the frequent investors,

$$
K_{t}=(1-q) \frac{\mu_{t, t+1}(c)}{\phi \sigma_{t, t+1}^{2}(c)} \equiv b(c) \cdot Y_{t}
$$

is also linear with respect to $Y_{t}$.

Market clearing,

$$
D_{t}+K_{t}=Z_{t}-\mathbf{1} \cdot H_{t} \equiv g \cdot Y_{t},
$$

therefore applies if and only if $c$ solves the nonlinear equation

$$
a(c)+b(c)=g .
$$

My Stanford University research assistant, Kevin Wu, provided a simple and rapid numerical procedure for determining a solution $c$ to (4) for the special case in which $Z_{t}$ is itself autoregressive and independent of $X$, while $X$ is an i.i.d. process. I will illustrate with examples based on this case.

\footnotetext{
${ }^{8}$ The harmonic mean of a strictly positive real-valued function $f$ on some measure space with measure $m$ is defined by $\left(\int f^{-1}(x) m(d x)\right)^{-1}$.
} 


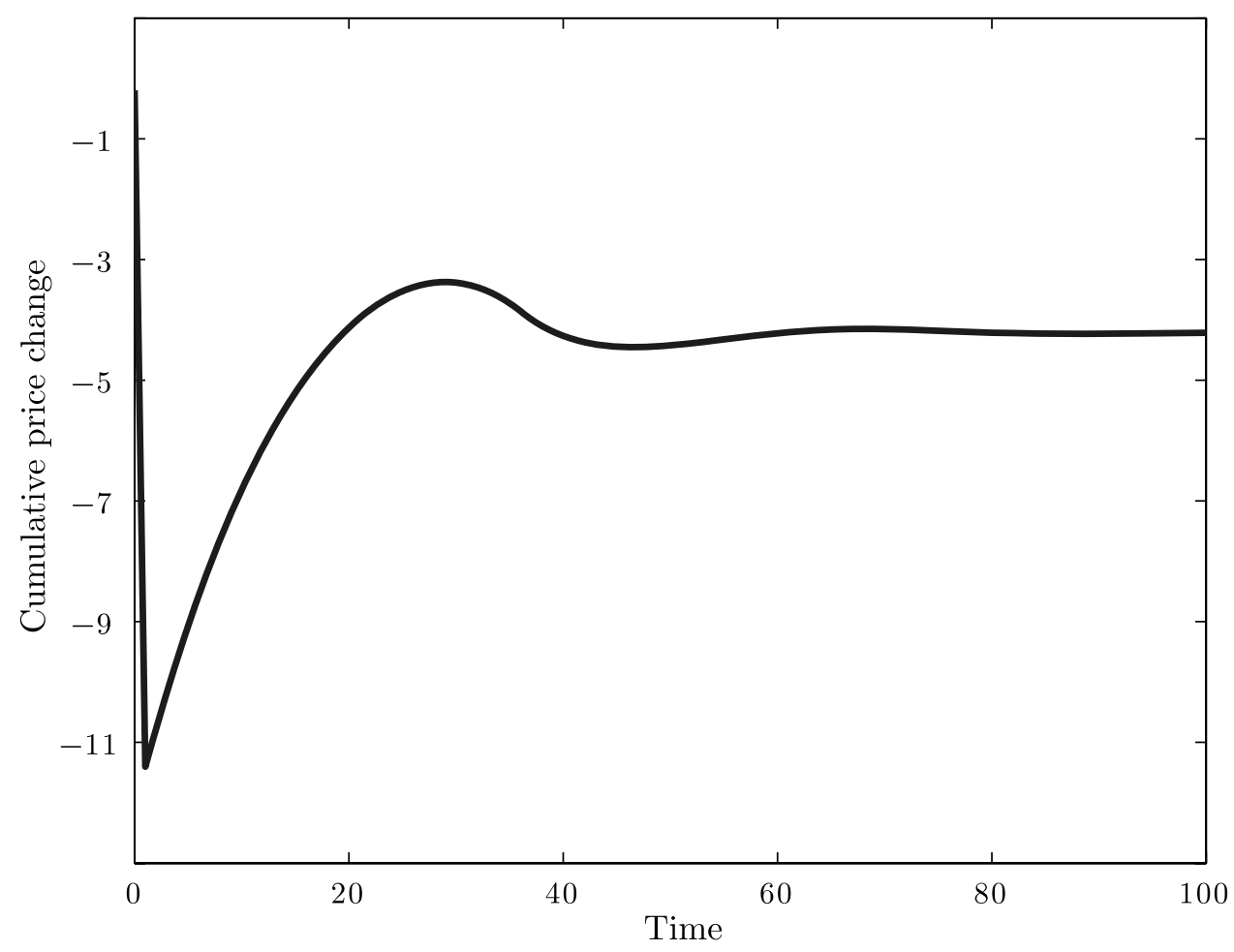

Figure 5. The price path associated with a supply shock on date 1 for the model and parameters described in the text. The parameters are provided on page 1252 of the text.

\section{A. A Surprise Supply Shock}

First, I consider the case of a "surprise supply shock." I suppose that at any time $t \geq 1$, the economy is as described above, with a constant Gaussian supply $Z_{t}=Z_{1}$, which has a conditional mean at time 0 of zero and a conditional variance of 0.1 . I take $X_{1}, X_{2}, \ldots$ to be i.i.d. with mean 0 and variance 0.1 . The system of equations determining the initial equilibrium price $S_{0}$ can then be solved based on a given initial condition for the vector $H_{0}$ of the initial lagged demands of infrequent investors. I take the case of zero lagged demands, $H_{0}=0$, and risk-aversion coefficients $\theta=\phi=1$. The per-period interest rate $r-1$ is $1 \%$. I assume that the fraction of infrequent investors is $q=0.8$ and that the infrequent investors make trading decisions once every $k=32$ periods. Figure 6 shows the effect of a "massive" supply shock at time 1 of size 2 . Of the total population of investors, the fraction available to absorb the supply shock at time 1 is

$$
1-q+\frac{q}{k}=0.225 \text {. }
$$

In order to provide a sufficient incentive for this relatively small mass of investors to absorb the supply shock, the equilibrium price must decline 


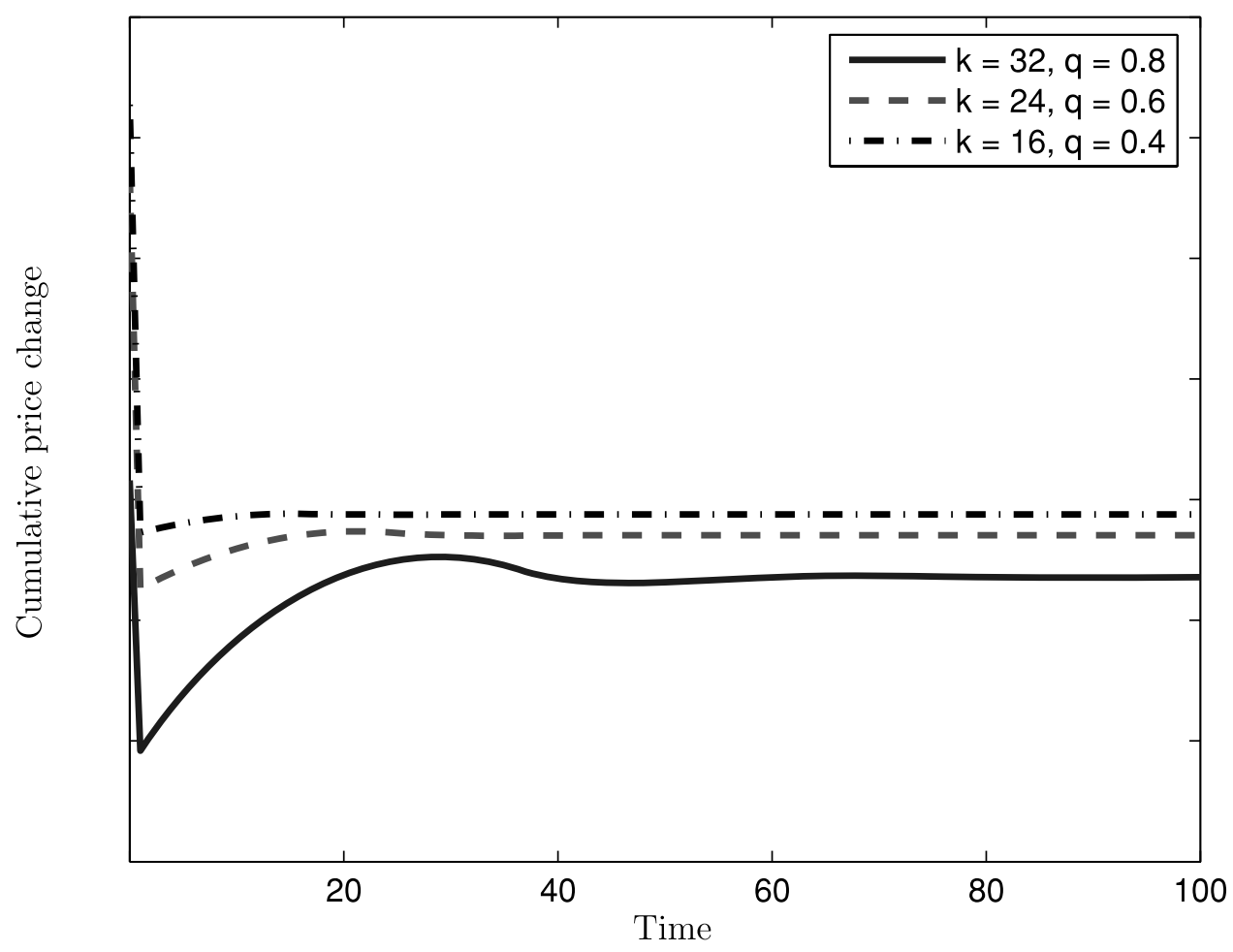

Figure 6. The price paths for the supply shock on date 1 considered in Figure 5, varying the inattentiveness parameters $q$ and $k$.

dramatically, as shown. All investors are solving a dynamic programming problem that incorporates the risk associated with owning the asset until they decide to sell it, correctly anticipating the expected mean gain and variance of their equilibrium future wealth levels. The infrequent investors trading at time 1 understand they will be away from the market for 32 periods, by which time the price will have recovered substantially. They purchase a relatively large quantity in light of this price gain. Indeed, as illustrated, the cumulative effect of the strong appetite to buy of the limited-attention investors arriving in the subsequent periods, and the fact that they will hold their positions off the market for an additional $k$ periods, implies that the price will climb above its steady-state level before eventually converging. Subsequent decaying ripples in the price path are based on the same reasoning, applied to successively smaller demand and supply dislocations caused by nonsteady-state purchases and sales as the supply shock is gradually spread out evenly across the population of infrequent investors. In a setting in which inattentive investors optimally chose the nonstationary periods of their inattentiveness in response to the current investment opportunities, these "overshooting" effects would be dampened but, given a positive cost of attentiveness, not eliminated. 


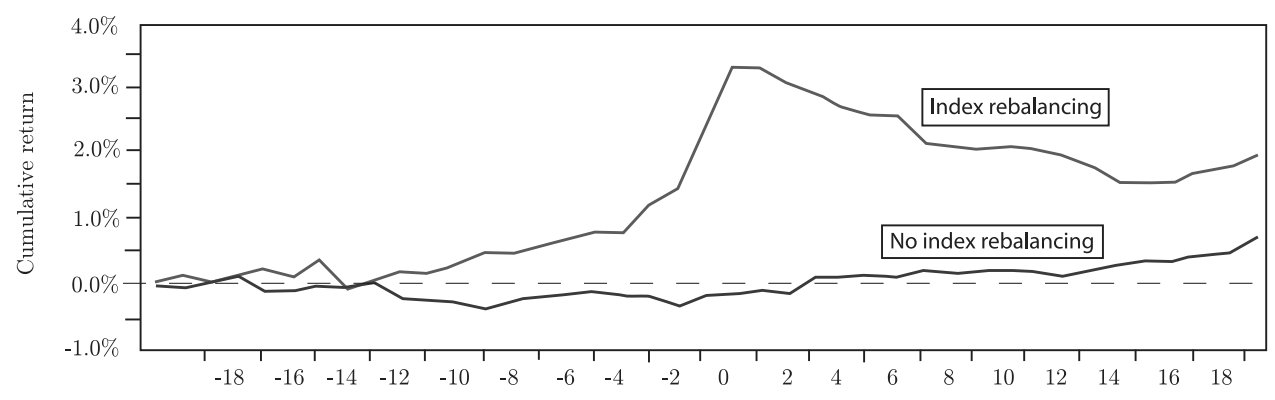

Figure 7. The average of the cumulative stock returns of acquirers, relative to the month of their mergers. Index rebalancing applies if the acquirer is in the S\&P 500 and the target is not. Source: Mitchell, Pulvino, and Stafford (2004).

Figure 6 shows the time signature of the price response to the same supply shock, with alternative choices for the parameters $q$ (fraction of inattentive investors) and $k$ (period of inattentiveness). The price impact and reversal effects are modulated in a natural way by increasing trading attentiveness.

A natural example of a relatively unanticipated supply shock is that associated with an index recomposition, such as that illustrated in Figure 1, for which the announcement date shortly precedes the effective date. A related supply shock occurs at the merger of a firm included in a major stock index with one that is not included in that index. Mitchell et al. (2004) explain that at such an effective date, index funds must increase their positions in the merged equity so that they hold the new version of that equity in proportion to its new larger total equity market capitalization. As illustrated in Figure 7, the price impact and reversal reflects a surge of demand for the equity that must be supplied by investors who are available for this purpose in the short run. Over time, the "shortage" of shares is addressed as additional supplies become available to the market. The price impact is not fully reversed, probably for the same reason that, on average, the price impact for an equity added to an index is not fully reversed. Chen et al. (2004) provide related empirical evidence for index additions, which seems to suggest that presence in a major stock index is associated with some permanent extra demand. Mitchell et al. (2002) show, as illustrated in Figure 7, that the mergers that do not involve index rebalancing motives do not experience significant price impacts and reversals.

\section{B. An Anticipated Supply Shock}

Figure 8 shows the time signature of the price impact and reversal associated with an anticipated supply shock at period 32 . We again take $k=32$ as our base case. The time-homogeneous model described above is solved from $t=1$, with initial lagged demands of 


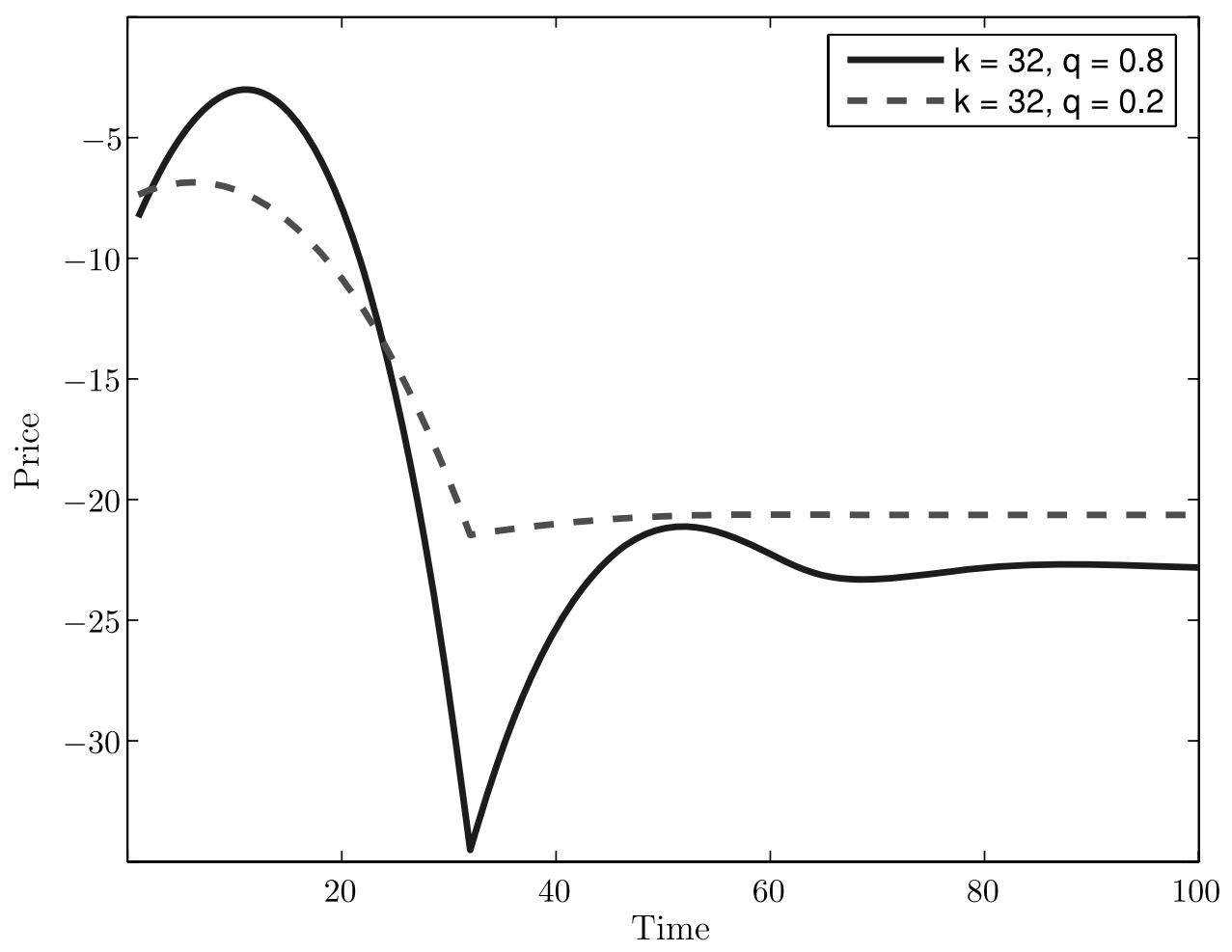

Figure 8. The modeled price path associated with an announcement on date 1 that a block sale occurs on date 32. The model and parameters are described in the text.

$$
\begin{aligned}
& H_{1,1}=10, \\
& H_{1, i}=\frac{-10}{k-2}, \quad i>1,
\end{aligned}
$$

so that the total of the lagged demands is zero, with a large amount, 10 units, of the asset due to be released into the market by investors who will not re-enter the market for 31 time periods. This is analogous to a large issuance of securities at period 32 that is anticipated by all investors because $H_{t}$ is part of the state vector upon which all investors condition when determining conditional means and variances. All other parameters are as in the previous example of a surprise supply shock. In particular, we take $q=0.8$. Because investors are aware in advance that a large supply of the asset will be released at period 32 , the equilibrium price declines in advance of the issuance. Before the price begins to decline, however, it must rise somewhat in order to absorb the small demand shocks each period of size $10 /(k-2)$ and to compensate frequent investors for buying the asset from arriving infrequent investors, who are anxious to sell because of the dramatic price declines they anticipate between periods 1 and 33, periods 2 and 34, periods 3 and 35, and so on. Eventually, however, 


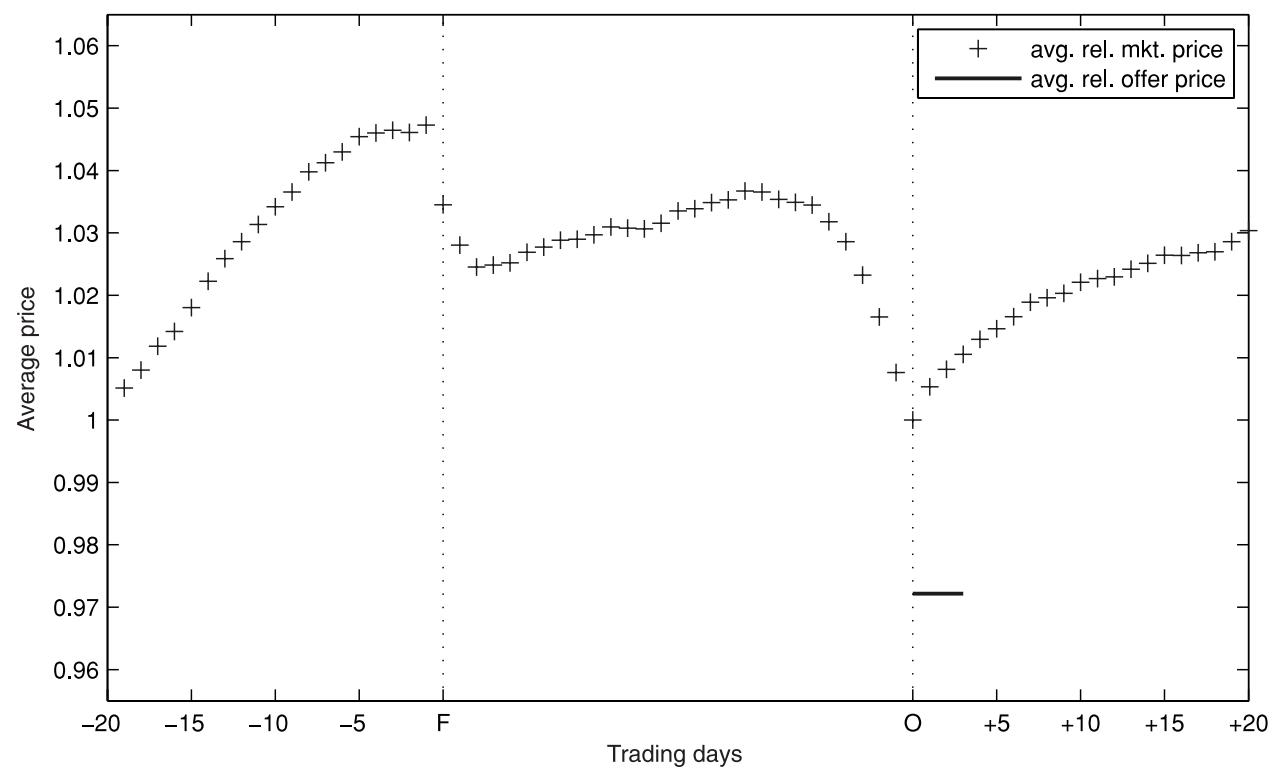

Figure 9. Average price dynamics around secondary equity issuances. The figure, kindly supplied to the author by Jan Peter Kulak, covers 3,850 U.S. industrial firms that undertook a firm-commitment public seasoned offering in the United States between 1986 and 2007. The plotted line shows the average across issuances of the ratio of the secondary market price of the equity to the closing price of the equity on the offering date. Because offerings differ in the number of trading days between the filing announcement and the offering date, the times between filing and offering date are rescaled to the average across the sample of the number of trading days between the filing and the issuance date. Source: Kulak (2008, unpublished data).

the incentive for all investors to sell is the price-dominating effect. Figure 8 illustrates how the price dynamics are modulated by investor attentiveness, by a comparison with the case in which only $20 \%$ of investors are inattentive.

I offer a few empirical examples, beyond the case of S\&P500 index deletions shown in Figure 1. Figure 9, from Kulak (2008), illustrates the average pattern of equity prices around the time of secondary equity issuances. That secondary offerings are made at substantial price concessions has been documented by Mikkelson and Partch (1985). At least as early as the work of Scholes (1972), researchers have focused on the presence of temporary price impacts at secondary equity issuances. Additional empirical evidence is offered by Loughran and Ritter (1995), Chaisurote (2008), and Gao and Ritter (2009).

Figure 10, provided to the author by Hongjun Yan, shows the impact (in terms of yield elevation) on U.S. Treasury notes of auction supply shocks. As suggested by my simple general equilibrium model, the price of the note goes down as the date of the anticipated new supply approaches, and then recovers in subsequent days. Indeed, Fleming and Rosenberg (2007) show that Treasury dealers adjust their positions to absorb issuance supply shocks. They describe how "dealers seem to be compensated for the risks associated with these inventory changes via price appreciation the subsequent week." 

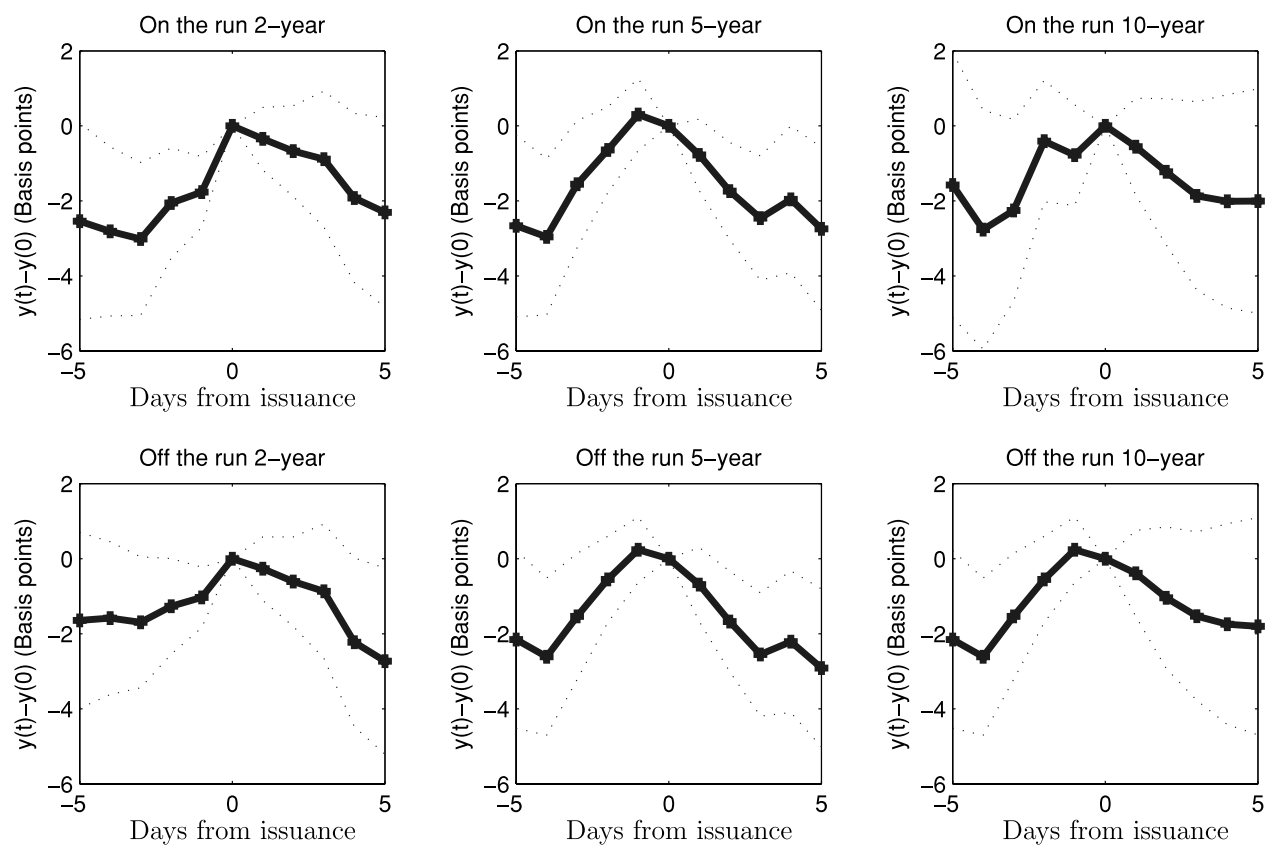

Figure 10. Yield elevation at the issuance of U.S. Treasuries, with 95\% "confidence" bands. The figure, kindly provided by Hongjun Yan, covers U.S. Treasury issuances from January 1980 to March 2008. Yields are based on averages of bid and ask prices obtained from the Center for Research in Security Prices. Auction dates are from the U.S. Treasury Department. The sample includes 332 2-year note auctions, 210 5-year note auctions, and 132 10-year note auctions. For each maturity, the differences between the yield on the issuance date and the yield on dates within 5 days of the issuance date are averaged across issuances, for both on-the-run and off-the-run notes. Source: Lou, Yan, and Zang (2010).

Figure 11, from Newman and Rierson (2003), illustrates that the effect described in the simple model, and in evidence in our previous two examples, has spill-over effects in related asset markets. When a large European telecom company scheduled a significant issuance of bonds during the period 1999-2001, the entire related market for European telecom bonds suffered an adverse price impact that increased as the issuance date approached, and then subsided. Figure 11 is the estimated path of price impacts on the yields of European Telekom issuers, not including Deutsche Telekom, associated with a particular 16-billion-euro issuance by Deutsche Telekom.

\section{Incompletely Observed Supply Shocks}

Using an ingenious new approach to measuring supply shocks to equity markets, Coval and Stafford (2007) isolated the degree to which redemptions by mutual fund investors cause individual equities held across various mutual funds to suffer from liquidation "fire sales," meaning significant unanticipated 


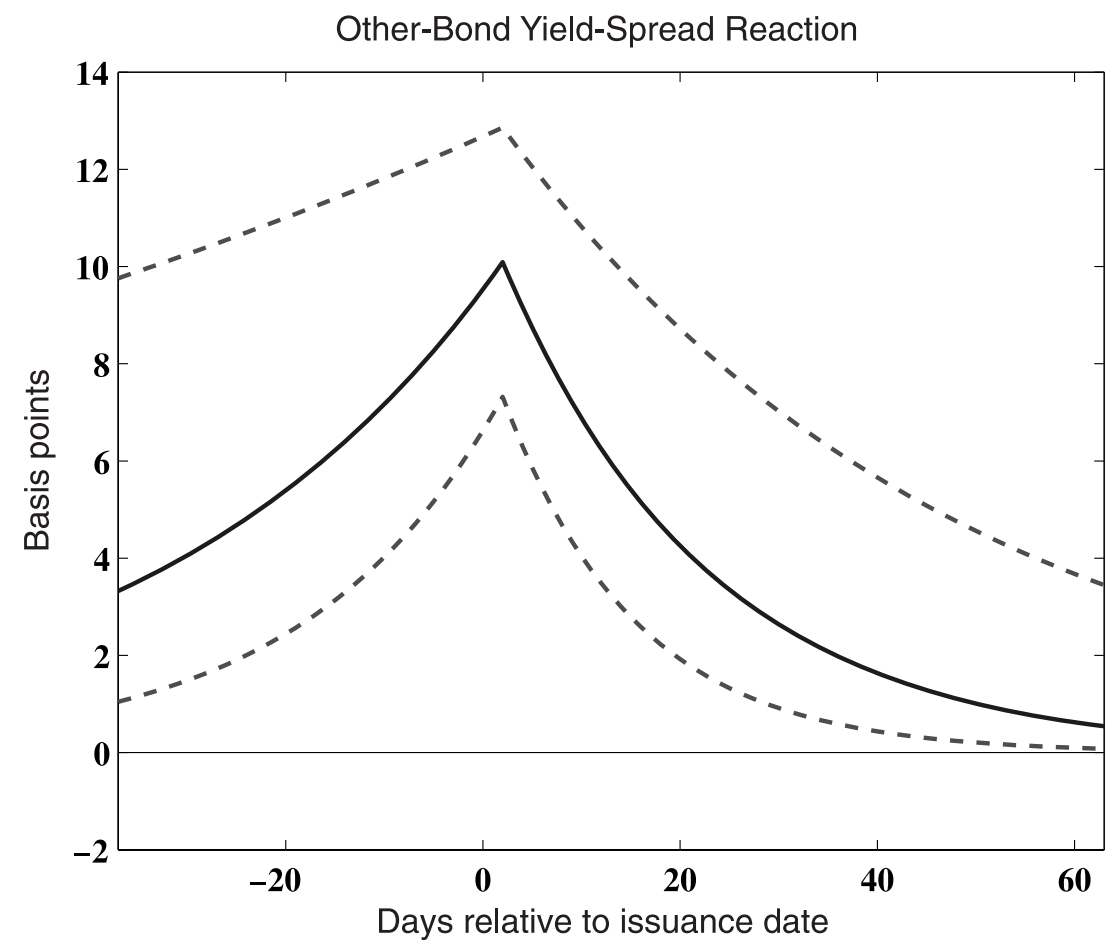

Figure 11. Capital immobility in the Telecom debt market. The estimated impacts on the yields of European Telekom issuers, not including Deutsche Telekom, associated with a particular 16-billion-euro issuance by Deutsche Telekom, using an econometric method explained by Newman and Rierson (2003). Source: Newman and Rierson (2003).

sales that are not subject to discretion with respect to timing. If only a limited pool of investment capital is immediately available to purchase these equities, our theory suggests that these equities should suffer from price declines exceeding those of a neoclassical equilibrium model, with a reversal of at least some of this price impact over subsequent months. Coval and Stafford (2007) find just such an effect, and a mirrored effect for demand shocks.

Figure 12, from Edmans, Goldstein, and Jiang (2009), illustrates the average of price impacts and reversals associated with large mutual fund redemptions, following a measurement approach modified slightly from that of Coval and Stafford (2007). Further evidence of this sort, for emerging-market funds, was found by Jotikasthira, Lundblad, and Ramadorai (2009).

One may have some concern, when interpreting the price impact of these fire sales, over the inability of investors to contemporaneously observe the supply shocks. (The mutual fund redemptions are not disclosed for some time, as explained by Coval and Stafford (2007), and the measurement of the combined effect across mutual funds on individual equities is, moreover, a difficult calculation.) Consider, for example, a hypothetical market in which all investors 


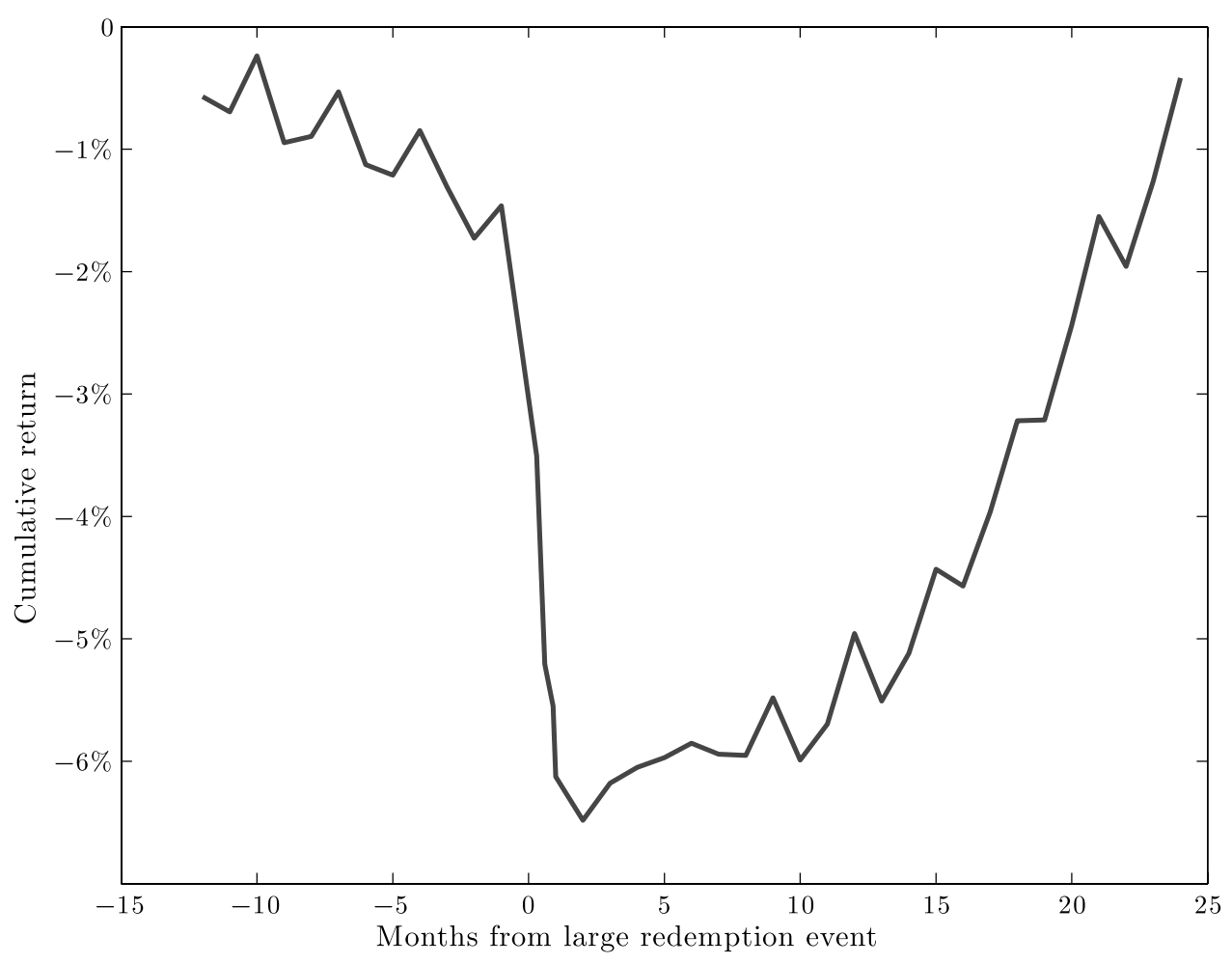

Figure 12. Average cumulative return of equities held by mutual funds experiencing large redemptions, counting months from the date of the large-redemption event. Mutual fund flow data from Thompson Financial were used by Edmans, Goldstein, and Jiang (2009) to calculate net outflows from each equity and each mutual fund. Total outflows across mutual funds, normalized by trading volume, determine "price pressure indices" for each equity, according to a specification stated by Edmans, Goldstein, and Jiang (2009). The cumulative returns plotted are those of equities in the top decile according to price pressure, as of the zero date. Source of cumulative return data: Edmans, Goldstein, and Jiang (2009).

are attentive to investment opportunities at all times, but with some investors (such as mutual funds) who are forced to liquidate large asset positions on short notice for reasons unrelated to news about the future cash flows of these assets, as postulated by Coval and Stafford (2007). Suppose further that such a liquidation event is not publicly reported and there is at any time the potential for some investors to receive adverse information concerning future asset cash flows. In this setting, the equilibrium price of the asset would drop at the time of the supply shock, simply because all other investors must absorb the supply shock, and they would require a price concession in order to do so. With rational expectations and learning from the price drop, all investors would assign some probability to the event that an adverse informational event had just occurred. If investors are unable to immediately identify whether the price drop is due to the arrival of adverse information or due to an unanticipated supply shock, 
then it would take time for them to improve their inference by observing cash flows and other information, including some information regarding magnitudes of redemptions. Over time, conditional on a liquidation event (as captured by Coval and Stafford (2007), as opposed to an informational event) the conditional probability that the price drop was due to the arrival of adverse private information would decline and the price would recover in expectation, creating a price path perhaps somewhat like that of Figure 12. A suitable specialization of the neoclassical model of He and Wang (1995) could be used to analyze price dynamics in this setting.

The identification problem that I have just described may come down to magnitudes, and may require additional theoretical and econometric research. The price impacts found by Coval and Stafford (2007), like those illustrated in Figure 12, seem quite large to be explained largely by a model with perfect capital mobility in which there are both liquidation shocks and information shocks.

\section{Concluding Remarks}

My objective is a conceptual framework for the dynamics of asset prices in settings in which, at a particular point in time, only a subset of investors are actively making a neoclassical tradeoff between the marginal value of consumption and the marginal value of wealth invested in each of the available assets. A primary reason for this form of limited participation is the cost of maintaining perfect attentiveness to trading opportunities. In some cases, expressing a trading decision requires access to a natural trading counterparty (especially in over-the-counter markets) that is difficult to arrange on short notice or is limited by the capitalization of intermediaries. The key implication is that supply or demand shocks must be absorbed on short notice by a limited set of investors. The risk aversion or limited capital of the currently available investors, including intermediaries, leads them to require a price concession in order absorb the supply or demand shock. They plan to "lay off" the associated risk over time as other investors become available. As a result, the initial price impact is followed by a price reversal that may occur over an extended period of time. The amplitude of the price impact as well as the duration and speed of the price reversal vary considerably across markets.

The general perspective I have taken is that asset prices can move away from "fundamental" values if capital is not perfectly mobile. More precisely, equilibrium asset-pricing fundamentals include state variables determining the immediate and future availability of capital supplied by various investors across various markets. These additional state variables may include the capitalization of intermediaries as well as the positions of investors that are not currently active, for each type of investor and possibly by vintage of investment activity date, as in my simple illustrative model of Section V. For example, I have drawn on research indicating how the positions held by index funds, specialists, insurance companies, inattentive investors, limit-order submitters, and others play a special role in asset price dynamics, because of slow 
moving capital, beyond the role they would play in a classical setting in which every investor stands ready at all times to equate marginal rates of substitution across consumption and all types of investments. Additional evidence of the effect on asset price dynamics of specific-investor positions has been offered by Greenwood (2005b), Bekaert, Harvey, and Lundblad (2007), Bartram, Griffin, and Ng (2010), Jotikasthira et al. (2009), Chaisurote (2008), and Lou (2009). Models based on imperfect search are especially natural for dealerintermediated and OTC markets. Capturing trading delays is crucial for a realistic model of price dynamics for almost any market, at least when considering returns over time periods shorter than the length of time over which many investors are inattentive. Further, the time signatures of price responses to supply shocks help identify the degree and form of capital immobility.

\section{Appendix: Stationary Model Solution}

This appendix, which provides some additional details and generalizations of the model of Section V, was completed with the assistance of my research assistant Felipe Varas.

Let $H_{t}=\left(D_{t-1}, D_{t-2}, \ldots, D_{k-1}\right)^{\top}$ be the vector of quantities held off the market by slow investors. The state vector is $Y_{t}=\left(\Phi_{t}^{\top}, H_{t}^{\top}\right)^{\top}$, where $\Phi_{t}$ is an $n$ dimensional vector autoregressive (VAR) process satisfying

$$
\Phi_{t+1}=\Lambda \Phi_{t}+\Sigma^{1 / 2} \epsilon_{t+1}
$$

for some $n$-dimensional vector $\epsilon_{t}$ of i.i.d. normal random variables.

The asset supply and dividend processes are of the form $Z_{t}=\beta_{Z}^{\top} \Phi_{t}$ and $X_{t}=\beta_{X}^{\top} \Phi_{t}$, respectively, for given $n$-dimensional coefficient vectors $\beta_{Z}$ and $\beta_{X}$. I assume a linear equilibrium with asset price of the form $S_{t}=c^{\top} Y_{t}$, inattentiveinvestor demand $D_{t}=a^{\top} Y_{t}$, and frequent investor demand $K_{t}=b(a, c)^{\top} Y_{t}$. Under these assumptions, the dynamics of $Y_{t}$ are given by

$$
Y_{t+1}=A(a) Y_{t}+B \epsilon_{t+1}
$$

where

$$
A(a)=\left(\begin{array}{ccc}
\Lambda & & \mathbf{0}_{n \times(k-1)} \\
& a^{\top} & \\
\mathbf{0}_{(k-2) \times n} & I_{(k-2) \times(k-2)} & \mathbf{0}_{(k-2) \times 1}
\end{array}\right)
$$

and

$$
B=\left(\begin{array}{c}
\Sigma^{1 / 2} \\
\mathbf{0}_{(k-1) \times n}
\end{array}\right) .
$$


We can calculate the conditional moments

$$
\begin{aligned}
E\left(Y_{t+k} \mid Y_{t}\right) & =A(a)^{k} Y_{t} \\
\operatorname{var}\left(Y_{t+k} \mid Y_{t}\right) & =\sum_{j=1}^{k}\left(A(a)^{j-1} B\right)\left(A(a)^{j-1} B\right)^{\top} \\
\operatorname{cov}\left(Y_{t+i}, Y_{t+j} \mid Y_{t}\right) & =\sum_{l=1}^{\min (i, j)}\left(A(a)^{i-l} B\right)\left(A(a)^{j-l} B\right)^{\top}
\end{aligned}
$$

I let $\theta$ and $\phi$ denote the harmonic means of the absolute risk aversions of the inattentive and attentive investors, respectively, and let $r$ denote the gross rate of return on risk-free investments. Because the inattentive investors are assumed to reinvest dividends at the risk-free rate until the next trading date, their demand at date $t$ is

$$
D_{t}=\frac{q}{k} \frac{E_{t}\left(R_{t+k}\right)-r^{k} S_{t}}{\theta V_{t}\left(R_{t+k}\right)},
$$

where $E_{t}$ and $V_{t}$ denote conditional mean and variance, respectively, given $Y_{t}$, and where

$$
R_{t+k}=S_{t+k}+\sum_{i=1}^{k} r^{k-i} X_{t+i}
$$

The frequent investor demand is

$$
K_{t}=(1-q) \frac{E_{t}\left(S_{t+1}+X_{t+1}\right)-r S_{t}}{\phi V_{t}\left(S_{t+1}+X_{t+1}\right)} .
$$

We let $\Gamma=\left(\beta_{X}^{\top}, 0\right)^{\top}$, so $X_{t}=\Gamma^{\top} Y_{t}$. Using the equilibrium conjecture,

$$
\begin{aligned}
E_{t}\left(R_{t+k}\right)= & \left(c^{\top} A(a)^{k}+\sum_{i=1}^{k} r^{k-i} \Gamma^{\top} A(a)^{i}\right) Y_{t} \\
V_{t}\left(R_{t+k}\right)= & c^{\top} V_{t}\left(Y_{t+k}\right) c+\sum_{i=1}^{k} r^{k-i} \Gamma^{\top} \operatorname{cov}_{t}\left(Y_{t+k}, Y_{t+i}\right) c \\
& +\sum_{i=1}^{k} r^{k-i} c^{\top} \operatorname{cov}_{t}\left(Y_{t+i}, Y_{t+k}\right) \Gamma+\sum_{i=1}^{k} \sum_{j=1}^{k} r^{2 k-i-j} \Gamma^{\top} \operatorname{cov}_{t}\left(Y_{t+i}, Y_{t+j}\right) \Gamma
\end{aligned}
$$

Similarly,

$$
\begin{aligned}
& E_{t}\left(S_{t+1}+X_{t+1}\right)=(c+\Gamma)^{\top} A(a) Y_{t} \\
& V_{t}\left(S_{t+1}+X_{t+1}\right)=(c+\Gamma)^{\top} B B^{\top}(c+\Gamma)
\end{aligned}
$$


In order to simplify notation, we let $\sigma_{1}^{2}(c)=V_{t}\left(S_{t+1}+X_{t+1}\right)$ and $\sigma_{k}^{2}(a, c)=$ $V_{t}\left(R_{t+k}\right)$. The market clearing condition

$$
D_{t}+K_{t}=Z_{t}-\mathbf{1} \cdot H_{t} \equiv g \cdot Y_{t}
$$

reduces to $a+b(a, c)=g$, where $g=\left(\beta_{Z}^{\top},-\mathbf{1}_{1 \times k-1}\right)^{\top}$. Thus, matching the demand coefficients,

$$
a=\frac{q}{k} \frac{\left(A(a)^{\top k}-r^{k} I\right) c+\sum_{i=1}^{k} r^{k-i} A(a)^{\top k} \Gamma}{\theta \sigma_{k}^{2}(a, c)}
$$

and

$$
b(a, c)=(1-q) \frac{\left(A(a)^{\top}-r I\right) c+A(a)^{\top} \Gamma}{\phi \sigma_{1}^{2}(c)} .
$$

Finally, using the equilibrium conditions, $(a, c)$ must solve

$$
\begin{gathered}
a=\frac{q}{k} \frac{\left(A(a)^{\top^{k}}-r^{k} I\right) c+\sum_{i=1}^{k} r^{k-i} A(a)^{\top^{k}} \Gamma}{\theta \sigma_{k}^{2}(a, c)} \\
c=\left(A(a)^{\top}-r I\right)^{-1}\left(\frac{\phi \sigma_{1}^{2}(c)}{1-q}(g-a)-A(a)^{\top} \Gamma\right) .
\end{gathered}
$$

These equations are to be solved numerically. I have not demonstrated the existence of solutions. Because the price of the asset is in principle the present sum of discounted future cash flows over an infinite horizon, one anticipates an existence condition for solutions that is based on a sufficiently large $r$, with controls on $\Lambda$ and $\Sigma$.

\section{REFERENCES}

Abel, Andrew B., Janice C. Eberly, and Stavros Panageas, 2009, Optimal inattention to the stock market with information costs and transactions costs, Working paper, University of Pennsylvania.

Adrian, Tobias, Erkko Etula, and Hyun Song Shin, 2009, Risk appetite and exchange rates, Working paper, Federal Reserve Bank of New York.

Adrian, Tobias, Emanuel Moench, and Hyun Song Shin, 2010, Financial intermediation, asset prices, and macroeconomics dynamics, Working paper, Federal Reserve Bank of New York.

Alvarez, Fernando, Luigi Guiso, and Francesco Lippi, 2010, Durable consumption and asset management with transaction and observation costs, Working paper, University of Chicago.

Alvarez, Fernando, Francesco Lippi, and Luigi Paciello, 2010, Optimal price setting with observation and menu costs, Working paper, University of Chicago.

Ameriks, John, and Stephen Zeldes, 2004, How do household portfolio shares vary with age? Working paper, Columbia University.

Andrade, Gregor, Charles Chang, and Mark Seasholes, 2005, Predictable reversals, cross-stock effects, and the limits of arbitrage, Working paper, Haas School of Business, University of California.

Ashcraft, Adam, and Darrell Duffie, 2007, Systemic dynamics in the federal funds market, American Economic Review, Papers and Proceedings 97, 221-225. 
Bacchetta, Philippe, and Eric van Wincoop, 2010, Infrequent portfolio decisions: A solution to the forward discount puzzle, American Economic Review (forthcoming).

Banerjee, Snehal, and Jeremy Graveline, 2010, The cost of short-selling liquid securities, Working paper, University of Minnesota.

Bartram, Söhnke M., John Griffin, and David Ng, 2010, How important is foreign ownership for international stock co-movement? Working paper, Wharton School.

Bekaert, Geert, Campbell R. Harvey, and Christian Lundblad, 2007, Liquidity and expected returns: Lessons from emerging markets, Review of Financial Studies 20, 1783-1831.

Biais, Bruno, Pierre Hillion, and Chester Spatt, 1995, An empirical analysis of the limit order book and the order flow in the Paris Bourse, Journal of Finance 50, 1655-1689.

Biais, Bruno, and Pierre-Olivier Weill, 2009, Liquidity shocks and order book dynamics, Working paper, UCLA.

Bilias, Yannis, Dimitris Georgarakos, and Michalis Haliassos, 2009, Portfolio inertia and stock market fluctuations, CEPR Discussion Papers.

Blocher, Jesse, Adam V. Reed, and Edward Dickersin Van Wesep, 2010, Connecting two markets: An equilibrium framework for shorts, longs and stock loans, Working paper, University of North Carolina.

Blume, Marshall, and Roger Edelen, 2001, On replicating the S\&P 500 index, Working paper, University of Pennsylvania-Finance Department.

Board of Governors of the Federal Reserve System, 2009, The Supervisory Capital Assessment Program: Overview of Results, May 7, 2009.

Born, Patricia, and Kip Viscusi, 2006, The catastrophic effects of natural disasters on insurance markets, Journal of Risk and Uncertainty 33, 55-72.

Brunnermeier, Markus, and Stefan Nagel, 2008, Do wealth fluctuations generate time-varying risk aversion? Micro-evidence on individuals' asset allocation, American Economic Review 98, 713-736.

Brunnermeier, Markus, and Lasse Heje Pedersen, 2009, Market liquidity and funding liquidity, Review of Financial Studies 22, 2201-2238.

Caballero, Ricardo, 1995, Near-rationality, heterogeneity, and aggregate consumption, Journal of Money, Credit and Banking 27, 29-48.

Chaisurote, Sith, 2008, Liquidity provision by international institutional investors: Evidence from Brazilian privatization, Working paper, Stanford University.

Chan, Wesley S., 2003, Stock price reaction to news and no-news: Drift and reversal after headlines, Journal of Financial Economics 70, 223-260.

Chen, Honghui, Gregory Noronha, and Vijay Singhal, 2004, The price response to S\&P 500 index additions and deletions: Evidence of asymmetry and a new explanation, Journal of Finance 59, 1901-1929.

Chen, Zhihua, Aziz A. Lookman, Norman Schürhoff, and Duane J. Seppi, 2009, Why ratings matter: Evidence from Lehman's index rating rule change, Working paper, CMU.

Chien, Yi Li, Harold L. Cole, and Hanno N. Lustig, 2010, Is the volatility of the market price of risk due to intermittent portfolio re-balancing? Working paper, UCLA.

Cohen, Lauren, and Dong Lou, 2010, Complicated trades, Working paper, Harvard Business School.

Constantinides, George, 1986, Capital market equilibrium with transactions costs, Journal of Political Economy 94, 842-862.

Coudert, Virginie, and Mathieu Gex, 2008, Contagion in the credit default swap market: The case of the GM and Ford crisis in 2005, Working paper, CEPII.

Coval, Joshua, and Erik Stafford, 2007, Asset fire sales (and purchases) in equity markets, Journal of Financial Economics 86, 479-512.

Davis, Mark, and Andrew Norman, 1990, Portfolio selection with transaction costs, Mathematics of Operations Research 15, 676-713.

D'Avolio, Gene, 2002, The market for borrowing stock, Journal of Financial Economics 66, 271-306.

Dellavigna, Stefano, and Joshua M. Pollet, 2009, Investor inattention and Friday earnings announcements, Journal of Finance 64, 709-749.

Duffie, Darrell, 1996, Special repo rates, Journal of Finance 51, 493-526.

Duffie, Darrell, 1999, Credit swap valuation, Financial Analysts Journal 55, 73-87. 
Duffie, Darrell, Nicolae Gârleanu, and Lasse Heje Pedersen, 2002, Securties lending, shorting, and pricing, Journal of Financial Economics 66, 307-339.

Duffie, Darrell, Nicolae Gârleanu, and Lasse Heje Pedersen, 2007, Valuation in over-the-counter markets, Review of Financial Studies 20, 1865-1900.

Duffie, Darrell, Gustavo Manso, and Semyon Malamud, 2010, Information percolation with segmented markets, Technical report, Stanford University.

Duffie, Darrell, and Bruno Strulovici, 2009, Capital mobility and asset pricing, Working paper, Stanford University.

Duffie, Darrell, and Tong-Sheng Sun, 1990, Transactions costs and portfolio choice in a discretecontinuous time setting, Journal of Economic Dynamics and Control 14, 35-51.

Edmans, Alex, Itay Goldstein, and Wei Jiang, 2009, Takeover activity and target valuations: Feedback loops in financial markets, Working paper, The Wharton School, University of Pennsylvania.

Engelberg, Joseph E., Adam V. Reed, and Matthew C. Ringgenberg, 2010, How are shorts informed? Short sellers, news, and information processing, Working paper, University of North Carolina.

Enz, Rudolph, 2001, The insurance cycle as an entrepreneurial challenge, Swiss Re Technical Publishing.

Etula, Erkko, 2009, Broker-dealer risk appetite and commodity returns, Working paper, Federal Reserve Bank of New York.

Feldhütter, Peter, 2009, The same bond at different prices: Identifying search frictions and selling pressures, Working paper, University of Copenhagen.

Fleming, Michael J., and Joshua V. Rosenberg, 2007, How do Treasury dealers manage their positions? Federal Reserve Bank of New York.

Froot, Ken, and Paul O'Connell, 1999, The pricing of U.S. catastrophe reinsurance, in K. Froot, ed., The Financing of Catastrophe Risk (University of Chicago Press, Chicago, IL), pp. 195-232.

Gabaix, Xavier, and David Laibson, 2001, The 6D bias and the equity premium puzzle, NBER Macroeconomics Annual 16, 257-312.

Gao, Xiaohui, and Jay R. Ritter, 2009, The marketing of seasoned equity offerings, Journal of Financial Economics (forthcoming).

Geczy, Christopher C., David K. Musto, and Adam V. Reed, 2002, Stocks are special too: An analysis of the equity lending market, Journal of Financial Economics 66, 241-269.

Goettler, Ronald, Christine Parlour, and Uday Rajan, 2005, Equilibrium in a dynamic limit order market, Journal of Finance 60, 2149-2192.

Goettler, Ronald, Christine Parlour, and Uday Rajan, 2008, Informed traders in limit order markets, Journal of Financial Economics 93, 67-87.

Goldstein, Michael, Edie Hotchkiss, and Erik Sirri, 2007, Transparency and liquidity: A controlled experiment on corporate bonds, Review of Financial Studies 86, 643-682.

Green, Richard C., Burton Hollifield, and Norman Schürhoff, 2007a, Dealer intermediation and price behavior in the aftermarket for new bond issues, Journal of Financial Economics 86, $643-682$.

Green, Richard C., Burton Hollifield, and Norman Schürhoff, 2007b, Financial intermediation and the costs of trading in an opaque market, Review of Financial Studies 20, 275-314.

Green, Richard C., Dan Li, and Norman Schürhoff, 2008, Price discovery in illiquid markets: Do financial asset prices rise faster than they fall? Working paper, Carnegie-Mellon University, Journal of Finance (forthcoming).

Greenwood, Robin, 2005a, Short and long term demand curves for stocks: Theory and evidence, Journal of Financial Economics 75, 607-650.

Greenwood, Robin M., 2005b, A Cross Sectional Analysis of the Excess Comovement of Stock Returns.

Gromb, Denis, and Dimitri Vayanos, 2002, Equilibrium and welfare in markets with financially constrained arbitrageurs, Journal of Financial Economics 66, 361-407.

Gromb, Denis, and Dimitri Vayanos, 2010, Limits of arbitrage: The state of the theory, Working paper, London School of Economics.

Grossman, Sanford, and Merton Miller, 1988, Liquidity and market structure, Journal of Finance $43,617-633$. 
Harris, Larry, and Eitan Gurel, 1986, Price and volume effects associated with changes in the S\&P 500: New evidence of price pressures, Journal of Finance 41, 815-830.

He, Hua, and Jiang Wang, 1995, Differential information and dynamic behavior of stock trading volume, Review of Financial Studies 8, 919-972.

He, Zhiguo, and Arvind Krishnamurthy, 2009, A model of capital and crises, Working paper, Northwestern University.

Hendershott, Terrence, and Albert Menkveld, 2009, Price pressures, Working paper, Haas School of Business.

Hendershott, Terrence, and Mark S. Seasholes, 2007, Market maker inventories and stock prices, American Economic Review 97, 210-214.

Jotikasthira, Chotibhak, Christian T. Lundblad, and Tarun Ramadorai, 2009, Asset fire sales and purchases and the international transmission of financial shocks, CEPR Discussion Papers.

Kaul, Aditya, Vikas Mehrotra, and Randall Morck, 2000, Demand curves for stocks do slope down: New evidence from an index weights adjustment, Journal of Finance 55, 893-912.

Lagos, R., G. Rocheteau, and P. O. Weill, 2009, Crashes and recoveries in illiquid markets, NBER Working paper, University of California at Los Angeles.

Lou, Dong, 2009, A flow-based explanation for return predictability, Working paper, Yale School of Managment.

Lou, Dong, Hongjun Yan, and Jinfan Zhang, 2010, Supply shocks in liquid markets, Working paper, Yale School of Management.

Loughran, Tim, and Jay R. Ritter, 1995, The new issues puzzle, Journal of Finance 50, 23-51.

Lusardi, Annamaria, 1999, Information, expectations, and savings, in H. Aaron, ed., Behavioral Dimensions of Retirement Economics (Brookings Institution Press/Russell Sage Foundation), pp. 81-115.

Lusardi, Annamaria, 2003, Planning and savings for retirement, Working paper, Dartmouth College.

Lynch, Anthony W., 1996, Decision frequency and synchronization across agents: Implications for aggregate consumption and equity return, Journal of Finance 51, 1479-1497.

Madhavan, Ananth, 2001, The Russell reconstitution effect, BlackRock, Inc., Investment Technology Group Working Paper No. 01-01.

Malliaris, Steven, and Hongjun Yan, 2010, Reputation concerns and slow-moving capital, Working paper, Yale School of Management.

Meli, Jeffrey, 2004, Do capital constraints on market makers matter? Evidence from the U.S. treasury market, Working paper, Graduate School of Business. University of Chicago.

Mikkelson, Wayne H., and M. Megan Partch, 1985, Stock price effects and costs of secondary distributions, Journal of Financial Economics 14, 165-194.

Mitchell, Mark, Lasse Heje Pedersen, and Todd Pulvino, 2007, Slow moving capital, American Economic Review, Papers and Proceedings 97, 215-220.

Mitchell, Mark, and Todd Pulvino, 2009, Arbitrage crashes and the speed of capital, Working paper, AQR Capital Management.

Mitchell, Mark, Todd Pulvino, and Erik Stafford, 2004, Price pressure around mergers, Journal of Finance 59, 31-63.

Mitchell, Olivia S., Gary R. Mottola, Stephen P. Utkus, and Takeshi Yamaguchi, 2006, The inattentive participant: Portfolio trading behavior in 401(k) plans, Working paper, University of Pennsylvania.

Myers, Stewart, 1984, The capital structure puzzle, Journal of Finance 39(4), 575-592.

Nagel, Stefan, 2009, Evaporating liquidity, Working paper, Stanford University.

Newman, Yigal, and Michael Rierson, 2003, Illiquidity spillovers: Theory and evidence from European telecom bond issuance, Working paper, Graduate School of Business, Stanford University.

Patterson, Michael, and Eric Martin, 2010, Wall Street takes break for Tiger Woods' apology: Chart of day, Bloomberg.

Petajisto, Antti, 2009, Why do demand curves for stocks slope down? Journal of Financial and Quantitative Analysis 44, 1013-1044.

Reis, Ricardo, 2006, Inattentive consumers, Journal of Monetary Economics 53, 1761-1800. 
Rinne, Kalle, and Matti Suominen, 2009, A structural model of short-term reversals, Working paper, Helsinki School of Economics.

Rinne, Kalle, and Matti Suominen, 2010, Short-term reversals, returns to liquidity provision and the cost of immediacy, Working paper, Helsinki School of Economics.

Rosu, Ioanid, 2009, A dynamic model of the limit order book, Review of Financial Studies 22, 4601-4641.

Scholes, Myron S., 1972, The market for securities: Substitution versus price pressure and the effects of information on share price, Journal of Business 45, 179-211.

Shleifer, Andrei, 1986, Do demand curves for stocks slope down? Journal of Finance 41, 579-590.

Stapleton, Richard C., and Marti G. Subrahmanyam, 1978, A multiperiod equilibrium asset pricing model, Econometrica 46, 1077-1096.

Weill, Pierre-Olivier, 2007, Leaning against the wind, Review of Economic Studies 74, 1329-1354.

Wolinsky, Asher, 1990, Information revelation in a market with pairwise meetings, Econometrica $58,1-23$.

Wurgler, Jeffrey, and Ekaterina Zhuravskaya, 2002, Does arbitrage flatten demand curves for stocks? Journal of Business 75, 583-608.

Zanjani, George, 2002, Pricing and capital allocation in catastrophe insurance, Journal of Financial Economics 65, 283-305.

Zhu, Haoxiang, 2010, Finding a good price in opaque over-the-counter markets, Working paper, Graduate School of Business, Stanford University. 